\author{
UNIVERSIDADE DE BRASÍLIA \\ FACULDADE DE EDUCAÇÃO FÍSICA \\ PROGRAMA DE PÓS-GRADUAÇÃO STRICTO-SENSU EM \\ EDUCAÇÃO FÍSICA
}

\title{
EFEITOS DA CRIOTERAPIA NA MODULAÇÃO DO DANO OXIDATIVO RESULTANTE DE LESÃO MUSCULAR EM RATOS
}

Angelina Freitas Siqueira

BRASÍLIA 
EFEITOS DA CRIOTERAPIA NA MODULAÇÃO DO DANO OXIDATIVO RESULTANTE DE LESÃO MUSCULAR EM RATOS

ANGELINA FREITAS SIQUEIRA

Dissertação apresentada à Faculdade de Educação Física da Universidade de Brasília, como requisito parcial para a obtenção do grau de Mestre em Educação Física.

ORIENTADOR: PROF. DR. JOÃO LUIZ QUAGLIOTTI DURIGAN 


\section{DEDICATÓRIA}

A meus pais, Bruno Cesar Siqueira (In memorian) e Jussara Carvalho Freitas, que em todos os momentos me fizeram acreditar que eu era capaz de fazer aquilo a que me propusesse na vida. As minhas escolhas me privaram do convívio familiar, mas sabendo que eu tinha asas eles me apoiaram em cada voo. Mesmo com a doença do meu pai durante o processo do mestrado, eles reforçavam que eu deveria cumprir com responsabilidade o compromisso assumido com a Instituição e os envolvidos. Enfim, essa conquista é graças a eles!

Pai, é com muita saudade que dedico essa dissertação especialmente ao senhor. O senhor que tinha uma visão sempre positiva da vida, regada pela fé em Deus e Nossa Senhora Aparecida. Carrego comigo o seu propósito de aproveitar a vida intensamente, mas a sua alegria de viver era única!

Mãe, a senhora é feita de um amor incondicional e de uma força incomum! Os seus ensinamentos me guiam, mas eu nada seria sem a o seu apoio e incentivo.

A senhora foi quem traçou para mim os planos da carreira acadêmica, mesmo antes desse ser um sonho meu. Estamos concluindo a primeira etapa! 


\section{AGRADECIMENTOS}

À Deus pois posso sentir a Sua presença constante em minha vida e assim mantenho minha fé renovada. Obrigada por me permitir essa conquista! Louvado seja o Seu nome!

Aos meus irmãos. Sempre tive muito orgulho de falar que são cinco: Paulo Cesar, Evandro, Bruno Cesar, Rodrigo e Rafael. Com as particularidades de cada um, vocês estão sempre me surpreendendo com gestos de preocupação, cuidado e carinho. Meu amor por vocês é eterno!

Ao meu orientador, professor João Durigan, por ter me dado essa chance de entrar no mundo da ciência. Admiro você como pesquisador, professor e grande crítico. Trabalhar com quem admiramos torna o processo mais agradável. Obrigada por todo o ensinamento! Que sua vida continue cheia de conquistas!

À professora Rita. A sua doçura associada à competência me cativaram desde o princípio. Você é exemplo de mulher, mãe, esposa e profissional! Observo você administrando tão bem todas essas "Ritas" e, assim, me sinto encorajada a persistir nesse caminho.

Ao Amilton. Desde o início admirava a sua retidão, responsabilidade e determinação. 0 mestrado trouxe você para a minha vida com toda a sua doação e paixão pela ciência. Agradeço pela sua parceria e por seus ensinamentos! Você tem sido fonte de inspiração para mim! Já vi muitas vitórias suas e tenho certeza que virão mais e mais, pois você merece!

Aos membros da banca, professores Gracielle, Lauro e Rinaldo, os quais aceitaram o convite com prontidão e tenho certeza que me ensinarão muito ainda nessa fase final!

Ao professor Martim e aos colegas do Laboratório de Força, por terem recebido no Laboratório com paciência e respeito essa iniciante em pesquisa. Sinto-me honrada em aprender a "fazer ciência" com vocês!

Aos professores, colegas e funcionários da Universidade de Brasília. Obrigada por fazerem do meu tempo na universidade, produtivo e enriquecedor!

Ao professor Gustavo Puntel, por ter acreditado nessa parceria e por toda a sua disponibilidade ao longo do processo de construção desse trabalho!

Aos professores e colegas da Edith Cowan University. Obrigada por essa chance que ultrapassa a experiência curricular! 
Àqueles que compartilham da paixão pela ciência, especialmente aos membros do Grupo de Pesquisa Plasticidade Músculo Tendínea. Obrigada pelos momentos de troca de experiência e pelas palavras de encorajamento!

A meus familiares e amigos que residem em Brasília. A minha mudança para Brasília foi necessária para conseguir realizar esse sonho e nos deu a chance de estreitarmos os laços. $O$ acolhimento de vocês foi fundamental para que eu me sentisse bem aqui!

À chefia e aos colegas de trabalho do Hospital Regional da Asa Norte. Muitas vezes minha disponibilidade para o trabalho tinha restrições devido aos compromissos acadêmicos e pude contar com a compreensão e colaboração de vocês para conseguir conciliar as atividades! Especialmente, agradeço ao Filippe, com quem entre as trocas de plantão tenho conversas prazerosas. Em uma dessas ocasiões, eu comentei sobre a minha vontade de fazer mestrado e com toda generosidade ele me apresentou o professor João Durigan.

A todas as pessoas que participaram direta ou indiretamente desta etapa da minha vida. Especialmente aos amigos e familiares que sempre acreditaram no meu sonho e tiveram uma palavra de apoio! 


\section{SUMÁRIO}

LISTA DE FIGURAS ................................................................................................... vii

LISTA DE SIGLAS ..................................................................................... ix

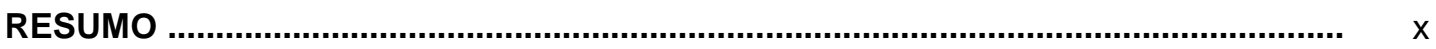

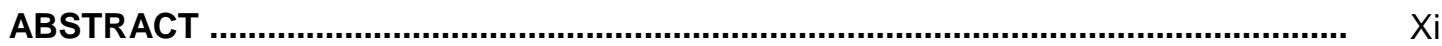

1.INTRODUÇÃO .............................................................................................. 12

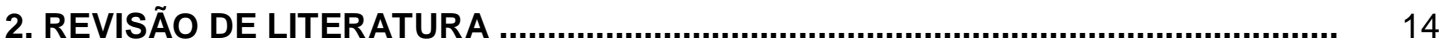

2.1 Lesão muscular ............................................................................................. 14

2.2 Resposta inflamatória associada à lesão muscular ............................................ 15

2.3 Dano oxidativo associado à lesão muscular ..................................................... 15

2.3.1 Mensuração de marcadores do dano oxidativo .................................................... 16

2.3.2 Mensuração da capacidade antioxidante ….................................................... 17

2.4 Crioterapia como agente terapêutico após lesão muscular .............................. 17

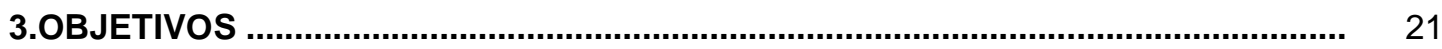

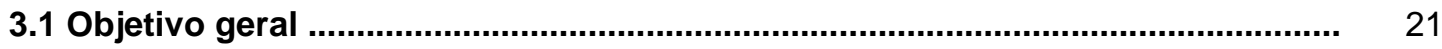

3.1 Objetivos específicos ….................................................................................. 21

4. MATERIAIS E MÉTODOS .................................................................................

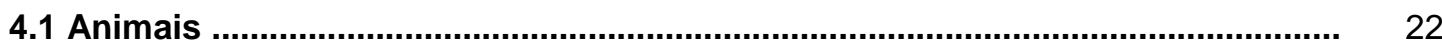

4.2 Grupos experimentais.............................................................................. 22

4.3 Protocolo de lesão muscular ........................................................................... 23

4.4 Protocolo de crioterapia ................................................................................. 24

4.5 Retirada dos músculos ................................................................................ 24

4.6 Área da lesão muscular .................................................................................. 25

4.7 Análise bioquímica do músculo esquelético homogeneizado............................ 25

4.8 Determinação dos marcadores de dano oxidativo e da viabilidade celular ....... $\quad 25$

4.8.1 Níveis de diclorofluoresceína oxidada ............................................................. $\quad 25$

4.8.2 Níveis de substâncias reativas ao ácido tiobarbitúrico ......................................... $\quad 26$

4.8.3 Níveis de redução do metil-tiazol-tetrazólio ....................................................... 27

4.9 Determinação da resposta de defesa antioxidante .......................................... $\quad 27$

4.9.1 Atividade da enzima superóxido dismutase ..................................................... 27

4.9.2 Atividade da enzima catalase .................................................................. 27

4.9.3 Níveis de grupos tióis não-proteicos .................................................................. 28

4.10 Determinação das proteínas ....................................................................... 28

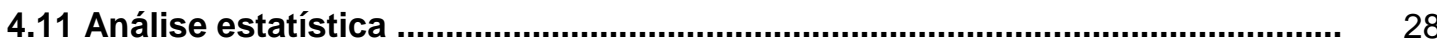

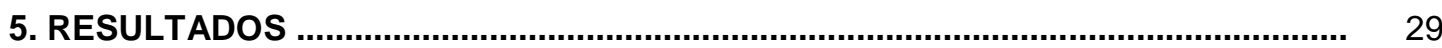

5.1 Histologia da regeneração muscular e quantificação do infiltrado inflamatório $\quad 29$

5.2 Dano oxidativo e viabilidade celular ................................................................ 30

5.3 Sistema antioxidante ....................................................................................... 32 


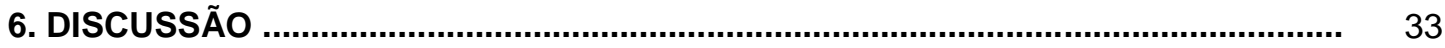

7. CONCLUSÃO ........................................................................................ 38

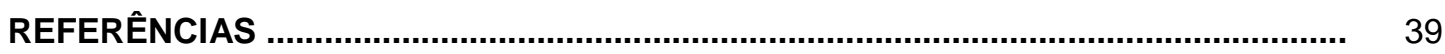

ANEXO I - Aprovação do Comitê de Ética em Experimentação Animal ................... 45 


\section{LISTA DE FIGURAS}

Página

Figura 1 - Desenho dos grupos experimentais........................................................ 22

Figura 2 - Esquema ilustrativo da criolesão no ventre do músculo TA........................... 23

Figura 3 - Desenho experimental do estudo....................................................... 24

Figura 4 - Fotomicrografia de cortes transversais de músculo TA de ratos, corados com azul de Toluidina, dos grupos lesão não tratados e tratados com crioterapia, avaliados nos dias 3, 7 e 14 após lesão musculoesquelética.

Figura 5 - Efeitos de aplicações intermitentes de crioterapia nas primeiras 72 horas após a lesão do músculo TA sobre o dano oxidativo.

Figura 6 - Efeitos de aplicações intermitentes de crioterapia nas primeiras 72 horas após a lesão do músculo TA sobre a resposta antioxidante. 


\section{LISTA DE SIGLAS}

ATP - Adenosina Trifosfato

CAT - Catalase

CK - Creatina quinase

CuZn-SOD - Cobre-zinco superóxido dismutase

DCFA-DA - Diclorofluoresceína-diacetato

DCF-RS - Diclorofluoresceína oxidada por espécies reativas

DCFH - Composto diclorofluoresceína

DNA - Ácido desoxirribonucleico

EC-SOD - Superóxido dismutase extracelular

EROs - Espécies reativas de oxigênio

GPx - Glutationa peroxidase

GSH - Glutationa reduzida

$\mathrm{HO}_{2} \bullet$ - Radical hidroperoxil

$\mathrm{H}_{2} \mathrm{O}$ - Água

$\mathrm{H}_{2} \mathrm{O}_{2}$ - Peróxido de hidrogênio

MDA - Malondialdeído

Mn-SOD - Manganês superóxido dismutase

MTT - Metil-tiazol-tetrazólio

$\mathrm{OH} \bullet--$ Radical hidroxila

$\mathrm{O}_{2} \cdot-$ - Radical ânion superóxido

SOD - Superóxido dismutase

TA - Tibial anterior

TBA - Ácido tiobarbitúrico

TBARS - Espécies reativas ao ácido tiobarbitúrico

- SH - Grupos tióis 


\section{RESUMO}

A proliferação de células inflamatórias após a lesão musculoesquelética interfere na extensão da lesão em decorrência da liberação de espécies reativas de oxigênio (EROs) e ativação de fosfolipases e proteases. A crioterapia é uma das mais recomendadas estratégias terapêuticas para o tratamento das lesões musculoesqueléticas. Apesar disso, há uma escassez de estudos que investigam o efeito da crioterapia no processo de regeneração e os resultados são inconsistentes e não confirmam a sua recomendação clínica. O objetivo do estudo foi analisar o efeito do crioterapia aplicada de modo intermitente, nas primeiras 72 horas após criolesão de músculo tibial anterior (TA) em ratos, sobre o infiltrado inflamatório e o dano oxidativo. Para isso, foram realizadas a análise histológica da densidade do infiltrado inflamatório; a determinação dos marcadores de estresse oxidativo, pelos níveis de diclorofluoresceína oxidada por espécies reativas (DCFRS), de espécies reativas ao ácido tiobarbitúrico (TBARS) e de metil-tiazol-tetrazólio (MTT) reduzido; e a determinação do sistema antioxidante, pela atividade enzimática de superóxido dismutase (SOD) e catalase (CAT) e níveis de grupos tióis (-SH) não-proteico, aos 3,7 e 14 dias após a lesão. A crioterapia reduziu o infiltrado inflamatório quando comparada à lesão não tratada e manteve os níveis do DCF-RS, TBARS e MTT reduzido próximos dos níveis do grupo controle. Assim como, a crioterapia manteve os níveis de SOD, CAT e -SH não-proteico em níveis similares ao do grupo controle. Concluimos que aplicações intermitentes de crioterapia, nas primeiras 72 horas após criolesão de músculo TA em ratos, reduziram o infiltrado inflamatório e o dano oxidativo.

Palavras-chave: crioterapia, inflamação, estresse oxidativo, músculo esquelético, fisioterapia. 


\begin{abstract}
Inflammatory cells can amplify the primary lesion by releasing the reactive oxygen species (ROS) and activating phospholipases and proteases on injured muscle. Cryotherapy is one of the most recommended therapies to treat skeletal muscle lesions. Nevertheless, studies that investigate cryotherapy on regeneration process are scarce and these studies comparing the effectiveness of cryotherapy on muscle regeneration are inconsistent. The aim of this study was analyze the effect of intermittent cryotherapy, during the first 72 hours after cryolesion of tibialis anterior (TA) muscle in rats, on inflammatory infiltration and oxidative damage. We analyzed histological inflammatory infiltration; determined oxidative stress biomarkers, such as diclorofluoresceine reactive substances (DFC-RS), thiobarbituric acid reactive substances (TBARS) and methyl thiazol tetrazolium (MTT) reduction levels; and determined antioxidative system action, by activities of superoxide dismutase (SOD) and catalase (CAT) and nonprotein thiol (-SH) non protein levels, on 3, 7 and 14 days after muscle lesion. Cryotherapy reduced the inflammatory infiltration and maintained the DCFRS, TBARS and MTT reduction levels close to the levels of control group. Additionally, the cryotherapy maintained the SOD and CAT activity and the -SH non-protein levels similar to the control group levels. In conclusion, the intermittent applications of cryotherapy, during the first 72 hours after cryolesion, reduced both the inflammatory infiltration and oxidative damage.
\end{abstract}

Key words: cryotherapy, inflammation, oxidative stress, skeletal muscle, physical therapy modalities. 


\section{INTRODUÇÃO}

O tecido muscular estriado esquelético apresenta alta suscetibilidade a lesões devido a sua intensa solicitação (1). As lesões musculoesqueléticas acarretam um alto custo à saúde pública, tanto no que se diz respeito à atenção médica, quanto ao custo indireto relacionado ao tempo de afastamento do trabalho (2). Independentemente da sua etiologia, inicia-se um processo orquestrado de regeneração muscular, o qual é dividido em três fases: fase de destruição e inflamação (0 to 72 horas), fase de reparo (3 dias a 4 semanas) e fase de remodelamento ( 3 semanas a 6 meses) (3). Durante a fase de destruição e inflamação, a proliferação de células inflamatórias no tecido lesado interfere na extensão da lesão em decorrência da liberação de espécies reativas de oxigênio (EROs) e ativação de fosfolipases e proteases $(4,5)$.

A lesão primária do musculoesquelético afeta simultaneamente os tecidos adjacentes, entre eles o tecido vascular. O comprometimento da microcirculação local impõe um desafio à sobrevivência do tecido devido à inadequada oferta de oxigênio e substratos como a glicose, assim como à inadequada remoção de metabólitos como o lactato (6). Além disso, um dano adicional ocorre após a restauração da perfusão da área hipoxêmica $(5,6)$. Essa lesão pelo mecanismo de isquemia-reperfusão é causada pela ação das EROs (7). Como potentes oxidantes, as EROs podem reagir irreparavelmente com os lipídeos, carboidratos, e até mesmo moléculas de ácido desoxirribonucleico (DNA), alterando suas estruturas e assim podendo comprometer a função celular (8). Os lipídeos são os primeiros alvos das EROs, tornando as membranas das células e das organelas vulneráveis à peroxidação lipídica. Felizmente, existe um complexo sistema antioxidante de combate a essas espécies reativas. Portanto, o processo subsequente dependerá de um aumento suficiente da defesa antioxidante para evitar a perda da função normal da célula (9).

Há uma variedade de estratégias terapêuticas para o tratamento das lesões musculoesqueléticas, entre elas a crioterapia é uma das mais recomendadas (10-12). O racional teórico para o uso da crioterapia na fase inicial da lesão é relacionado à redução do metabolismo local, impedindo a progressão da lesão secundária e consequentemente reduzindo o tempo de recuperação da lesão $(3,6)$. Alguns estudos, a maioria deles realizada em modelos animais, demonstraram os efeitos da crioterapia na redução do processo inflamatório e do dano oxidativo, entretanto os mecanismos envolvidos não são completamente compreendidos. A aplicação de crioterapia ( 3 sessões de 30min cada) após lesão musculoesquelética reduziu o processo inflamatório, em decorrência da redução da área de lesão secundária $(10,13)$. De maneira complementar, a aplicação de crioterapia (2 sessões de $5 \mathrm{~min}$ cada) após lesão musculoesquelética reduziu a concentração plasmática de marcador de dano muscular e permitiu estabelecer uma relação direta entre a resposta inflamatória e o dano oxidativo (9). De acordo com Puntel e colaboradores (2011), a crioterapia (2 sessões de $5 \mathrm{~min}$ cada) após a lesão musculoesquelética reduziu o dano oxidativo, em concordância com a redução dos prejuízos da função mitocondrial. E até 
mesmo a imersão em água gelada por 5 minutos, após dano muscular induzido por exercício em indivíduos saudáveis, reduziu o nível de peroxidação lipídica (15). As diferenças metodológicas entre os estudos demonstram claramente que não há um protocolo de crioterapia completamente estabelecido, sendo que importantes parâmetros são frequentemente escolhidos baseado em informações empíricas.

Além disso, até o momento, não foi encontrado nenhum estudo investigando os efeitos sobre o estresse oxidativo de um protocolo de crioterapia segundo as recomendações da prática clínica, isto é, aplicações intermitentes de crioterapia, durante as primeiras 72 horas após lesão musculoesquelética (16-19), período coincidente com a fase de destruição e inflamação. O presente estudo pretende investigar o efeito de aplicações intermitentes de crioterapia, nas primeiras 72 horas após criolesão de músculo tibial anterior (TA) em ratos, sobre o infiltrado inflamatório e o dano oxidativo, ao longo de 14 dias. Dessa forma, os resultados desse estudo fornecerão subsídios científicos ao uso clínico dos protocolos intermitentes de crioterapia no tratamento de lesão musculoesquelética aguda.

Baseado nos aspectos teóricos e nos achados prévios da literatura, a hipótese desse estudo é que seguindo as recomendações clínicas de aplicação intermitente da crioterapia nas primeiras 72 horas após a lesão muscular, essa estratégia terapêutica poderá minimizar o infiltrado inflamatório e o dano oxidativo após criolesão em músculo TA de ratos. 


\section{REVISÃO DE LITERATURA}

\subsection{Lesão muscular}

As lesões musculoesqueléticas estão entre as maiores causas de lesões observadas nas áreas de primeiros socorros, de saúde ocupacional e de medicina do esporte (20). Clinicamente, estão associadas a sinais e sintomas como dor muscular, edema, espasmo muscular, restrição de movimento e redução da força muscular $(21,22)$, sendo determinantes para o surgimento de limitações no desempenho das atividades de vida diária e ocupacionais dos indivíduos acometidos. Consequentemente, as lesões musculoesqueléticas têm determinado um importante impacto na saúde pública decorrente de um alto custo econômico (23), tanto no que se diz respeito à atenção médica, que inclui tratamento, exames complementares, internação e reabilitação; quanto ao custo indireto relacionado ao tempo de afastamento do trabalho (2).

$\mathrm{Na}$ prática, as lesões musculoesqueléticas agudas podem ser causadas basicamente por contusão, distensão e esforço muscular (21). Porém, independentemente do mecanismo de lesão, as respostas fisiológicas da lesão musculoesquelética aguda são semelhantes (24). Inicialmente, ocorrem alterações estruturais como a ruptura das fibras musculoesqueléticas e seus componentes, podendo atingir estruturas adjacentes, como os vasos sanguíneos e os nervos (16). Esse acometimento é conhecido como lesão primária, a qual afeta a homeostase, acarretando em morte e degradação celular (25).

A resposta fisiológica à lesão primária induz à lesão secundária, isto é, ao acometimento de células que não foram lesionadas diretamente pelo mecanismo (6). As causas de lesão secundária estão associadas à ativação enzimática e à hipóxia tecidual (10). Resumidamente, a ativação enzimática, como a de fosfolipases e de proteases, está relacionada ao aumento na liberação de enzimas pró-inflamatórias, especialmente pelos neutrófilos atraídos ao local da lesão a fim de iniciar o processo de regeneração tecidual (5). Por sua vez, a hipóxia tecidual está relacionada ao dano endotelial, o qual acarreta em redução do fluxo sanguíneo, devido à ativação da cascata de coagulação com aumento da viscosidade sanguínea, e em aumento da pressão extravascular pelo edema, podendo ocluir pequenos vasos e aumentar ainda mais a área isquêmica (25). Mesmo com essa redução de aporte de oxigênio, as células mantém a taxa metabólica celular e produzem EROs que favorecem ainda mais a lesão (26).

Dada essa magnitude das lesões musculoesqueléticas e o prejuízo funcional que acarretam, se faz necessário desenvolver estudos de tratamento e recuperação, a fim de reduzir o intervalo de regeneração muscular e garantir o retorno breve às atividades com desempenho individual máximo. Apesar da lesão primária não poder ser influenciada por recursos terapêuticos, a extensão da lesão secundária pode ser amenizada (26). Nesse contexto, a redução da resposta inflamatória e da hipóxia tecidual são decisivas para o efetivo tratamento das lesões musculoesqueléticas. 


\subsection{Resposta inflamatória associada à lesão muscular}

Após a lesão musculoesquelética, a regeneração tecidual ocorre em três fases interligadas e tempo-dependentes: fase de destruição e inflamação ( 0 a 72 horas), caracterizada pela ruptura e necrose das miofibrilas, formação de hematoma e reações celulares inflamatórias; fase de reparo (3 dias a 4 semanas), caracterizada pela fagocitose do tecido necrosado, regeneração das miofibrilas, produção de tecido conjuntivo cicatricial, assim como revascularização da área lesionada; e fase de remodelamento ( 3 semanas a 6 meses), caracterizada pela maturação das miofibrilas regeneradas, retração e reorganização do tecido cicatricial e recuperação da capacidade funcional do músculo $(3,27)$. A duração de cada uma das fases do reparo tecidual e a recuperação funcional do tecido muscular dependerá da extensão da lesão musculoesquelética (28).

A inflamação é uma resposta rápida à lesão musculoesquelética que envolve a coordenação entre o sistema imunológico e o tecido lesado (29). Em razão da lesão musculoesquelética, as membranas das fibras musculoesqueléticas sofrem ruptura e 0 conteúdo intracelular fica exposto, possibilitando a entrada de cálcio extracelular. Consequentemente, são ativadas proteases cálcio-dependentes, as quais contribuem para a degradação do tecido lesado e atraem neutrófilos para o sítio da lesão (30). Nas próximas 24-48h essas células são substituídas por macrófagos, os quais: fagocitam e removem o tecido necrosado; e liberam fatores de crescimento, citocinas e outros mediadores que ativam os mecanismos de regeneração como fatores miogênicos e células satélites (24). Esse processo de alteração morfológica da fibra muscular parece ser responsável pelos sinais e sintomas associados à lesão musculoesquelética, supracitados.

Esta relação entre a inflamação e regeneração muscular fornece base para argumentos teleológicos que a resposta inflamatória após a lesão musculoesquelética é uma resposta funcional benéfica (31). Entretanto, mais recentemente, compreende-se que uma resposta inflamatória inadequada ou exacerbada pode prejudicar o reparo do tecido danificado e pode resultar em uma deposição exagerada de tecido cicatricial no sítio da lesão, conduzindo à diminuição do desempenho ou mesmo a perda da função muscular (32).

\subsection{Dano oxidativo associado à lesão muscular}

O termo estresse oxidativo refere-se ao desbalanço entre a produção de prooxidantes e antioxidantes em favor dos prooxidantes. Os prooxidantes são espécies que causam ou promovem a oxidação e podem ser classificados como EROs ou espécies reativas de nitrogênio. Por sua vez, os antioxidantes são moléculas capazes de minimizar a formação dos prooxidantes e assim, inibir a oxidação das macromoléculas (33).

Em altas concentrações, os prooxidantes são perigosos para os tecidos, pois são substâncias altamente reativas, capazes de promover a oxidação e modificar os principais constituintes celulares, como os lipídeos, proteínas e ácidos nucleicos, acarretando no chamado dano oxidativo (33). Em concentrações moderadas, no entanto, os prooxidantes 
desempenham um papel importante como mediadores reguladores em processos de sinalização (8).

Após a lesão musculoesquelética o dano oxidativo é desencadeado pelo processo inflamatório $(33,34)$ e provavelmente agravado pela lesão de isquemia-reperfusão $(14,33)$. O processo inflamatório e a produção de espécies reativas após a lesão musculoesquelética estão intimamente interligados durante o processo de regeneração musculoesquelética. Há evidências de que os macrófagos e neutrófilos ativados na resposta inflamatória são responsáveis por uma produção massiva de EROs (8). Mas também que, as EROs são sinalizadoras fundamentais para orquestrar a inflamação, especialmente ativando o fator de transcrição fator nuclear kappa $\mathrm{B}(\mathrm{NF}-\kappa \mathrm{B})$ e assim, a expressão gênica que programa a adesão leucocitária (35). No que diz respeito à lesão de isquemia-reperfusão, tem-se observado que após a restauração da circulação local são liberadas especialmente EROs que causam peroxidação lipídica nas células endoteliais. Na fase seguinte, estas EROs provocam vasoconstrição e agregação de leucócitos e trombócitos e como resultado, aumentam a inflamação e danos celulares $(36,37)$.

\subsubsection{Mensuração de marcadores do dano oxidativo}

O limite fisiológico e patológico do dano oxidativo pode ser uma função da extensão, duração e/ou de origem celular das espécies reativas produzidas (33). A magnitude do dano oxidativo pode ser medida por meio de ensaios bioquímicos que quantifiquem a formação de produtos que indiretamente confirmam o aumento da geração de radicais livres e disfunção mitocondrial (38). Assim, é fortemente aconselhado que para a avaliação precisa e consistente do dano oxidativo mais de dois ensaios bioquímicos sejam realizados (39).

Uma das formas de estimar a produção de EROs é por meio da oxidação inespecífica da molécula diclorofluoresceína-diacetato (DCFA-DA) até sua forma oxidada por espécies reativas (diclorofluoresceína oxidada por espécies reativas, DCF-RS) (40). Já a extensão do dano oxidativo pode ser avaliada pela mensuração dos produtos de oxidação lipídica. A peroxidação lipídica é um processo complexo que envolve a interação de EROs com lipídeos (41). Os lipídeos constituem as biomembranas e são os alvos mais importantes para as espécies reativas, uma vez que sua estrutura molecular é abundante de ligações duplas (42). A peroxidação lipídica resulta em uma desorganização estrutural das biomembranas e a consequente perda de seletividade, podendo levar à morte celular (40). O malondialdeído (MDA) é um dos produtos finais da peroxidação lipídica. Um dos métodos mais comuns utilizados para estimar a peroxidação lipídica é a quantificação de MDA pelo método TBARS (espécie reativas ao ácido tiobarbitúrico - TBA) (33).

Outra forma de avaliar a extensão do dano oxidativo é pela mensuração da atividade de desidrogenases, as quais são fundamentais na catalisação de reações bioquímicas envolvidas na obtenção de energia intracelular. Em condições de funcionalidade adequada, as enzimas desidrogenases reduzem o metil-tiazol-tetrazólio 
(MTT) a formazan. Portanto, quando a célula morre, a habilidade de converter MTT em formazan é perdida, e por isso, esse ensaio é utilizado para avaliar o índice de viabilidade celular $(43,44)$.

\subsubsection{Mensuração da capacidade antioxidante}

O sistema antioxidante tem o papel de inativar, por meio de diferentes mecanismos, a ação dos prooxidantes de forma a impedir o dano oxidativo (40). A capacidade antioxidante tem sido frequentemente mensurada pelos mecanismos de defesa enzimática por meio da atividade da catalase (CAT) e superóxido dismutase (SOD) (45).

A SOD está presente sob pelo menos três formas principais, a cobre e zinco (CuZnSOD) localizada predominantemente no citosol celular, a manganês (Mn-SOD) de localização mitocondrial e a SOD extracelular (EC-SOD). A SOD catalisa a reação de dismutação do ânion superóxido $\left(\mathrm{O}_{2} \bullet-\right)$ em peróxido de hidrogênio $\left(\mathrm{H}_{2} \mathrm{O}_{2}\right)\left(\mathrm{O}_{2} \cdot-+\mathrm{O}_{2} \cdot-+2 \mathrm{H}^{+}\right.$ $\rightarrow \mathrm{H}_{2} \mathrm{O}_{2}+\mathrm{O}_{2}$ ). Como demonstrado SOD não previne a formação de $\mathrm{H}_{2} \mathrm{O}_{2}$. Porém, o $\mathrm{H}_{2} \mathrm{O}_{2}$ é mais estável que o ânion superóxido e pode difundir livremente entre os outros compartimentos celulares (45).

A desintoxicação de $\mathrm{H}_{2} \mathrm{O}_{2}$ é realizada pela CAT e pelas peroxidases. $\mathrm{O}$ papel da CAT é mais importante quando os níveis de $\mathrm{H}_{2} \mathrm{O}_{2}$ são baixos (45). A CAT está localizada em grande quantidade nos peroxissomas e catalisa a reação de degradação do $\mathrm{H}_{2} \mathrm{O}_{2}$ em moléculas de oxigênio e água (40). Em altas concentrações de $\mathrm{H}_{2} \mathrm{O}_{2}$, a enzima glutadiona peroxidase (GPx) que está vastamente distribuída nos tecidos, é responsável pela desintoxicação referente ao $\mathrm{H}_{2} \mathrm{O}_{2}$ às custas da oxidação em glutationa reduzida (GSH). Contudo, a GPx também é responsável pela desintoxicação de outros peróxidos (45).

A GSH faz parte do sistema de defesa oxidante não enzimático e desempenha um importante papel na manutenção do estado redução/oxidação celular. As alterações nos níveis de grupos tióis (-SH) não-proteicos são interessantes de serem determinadas no músculo esquelético em investigações da capacidade antioxidante já que a ação antioxidante da GSH depende da integridade do grupo -SH presente no resíduo de cisteína de sua molécula $(46,47)$.

\subsection{Crioterapia como agente terapêutico após lesão muscular}

A crioterapia é a aplicação terapêutica de frio, capaz de deslocar o calor da região a ser tratada induzindo o resfriamento local (48). O recurso terapêutico tem sido uma alternativa aceita e utilizada popularmente por ser, no geral, de baixo custo, fácil acesso e de simples aplicação. São várias as modalidades de crioterapia, sendo as mais comuns o pacote com gelo ou gel, imersão em água gelada, massagem com gelo, sprays refrigerantes e ar refrigerado (16).

Os profissionais de saúde e do esporte têm recomendado a crioterapia para o tratamento e reabilitação das lesões musculoesqueléticas agudas e crônicas, com o intuito de diminuir a dor, o edema e o tempo de recuperação $(16,19)$. Apesar da sua 
recomendação clínica e seu amplo uso, há controvérsia e pouco respaldo científico sobre a real eficácia da crioterapia durante a regeneração muscular em humanos $(50,51)$. Estudos em seres humanos são ainda escassos, pouco controlados e com dificuldades éticas de serem realizados, pois os resultados mais importantes deveriam ser obtidos por biópsia diretamente do músculo esquelético. Assim, o modelo animal se torna muito interessante, pois permite o maior controle experimental de todas as etapas e análises morfológicas e de biologia molecular diretamente no músculo envolvido.

O objetivo primário da utilização da crioterapia numa fase de cuidados imediatos pós-lesão muscular é minimizar sequelas adversas que estão relacionadas ao processo de lesão, tais como dor, edema, hemorragia, espasmo muscular $(16,27,52)$. Os efeitos fisiológicos induzidos pelo resfriamento tecidual incluem diminuição da temperatura, do metabolismo, da circulação sanguínea, da dor, do processo inflamatório e do dano oxidativo $(14,16,26,27,52-54)$.

De maneira geral, os estudos indicam que o resfriamento local leva a uma diminuição do metabolismo celular, proporcionando à célula um menor consumo de oxigênio, o que permite sua sobrevivência por um período maior de isquemia ou diminuição parcial da circulação $(6,16)$, evitando, assim, a hipóxia secundária e, consequentemente, a morte celular. Dessa forma, teoricamente, a extensão do tecido lesado torna-se menor e a resposta inflamatória, o estresse oxidativo, as proteínas livres e a pressão oncótica do tecido diminuem, por fim, o edema é reduzido e o tecido fica menos exposto à reação enzimática que acompanha a lesão $(48,55)$.

A maioria dos estudos que investigaram a resposta inflamatória e o dano oxidativo associado à lesão musculoesquelética aguda tem sido realizada com modelos animais. Esses estudos têm demonstrado que a crioterapia é efetiva na redução da resposta inflamatória, na modulação do estresse oxidativo, assim como na redução da lesão secundária. Puntel e colaboradores (2011) demonstraram que a aplicação de crioterapia (2 sessões com duração de 5 minutos cada) imediatamente após a lesão musculoesquelética, reduziu o dano oxidativo, o prejuízo das funções mitocondriais e a infiltração de neutrófilos. Em concordância, Carvalho e colaboradores (2010) demonstraram que a aplicação de crioterapia (2 sessões de 5 minutos cada), 30min após a lesão musculoesquelética, preveniu dano estrutural e funcional celular e reduziu a intensidade da resposta inflamatória. Recentemente, um estudo com humanos, o qual investigou o estresse oxidativo em resposta a exercício submáximo em ciclo ergômetro seguido por $5 \mathrm{~min}$ de uma única imersão em água gelada, encontrou resultados similares, apresentando redução da concentração dos biomarcadores da peroxidação lipídica (15).

Nesse contexto, um estudo demonstrou que 3 horas consecutivas de aplicação de crioterapia em um modelo de lesão de isquemia-reperfusão, reduziu a intensidade da resposta inflamatória e a disfunção mitocondrial (7). Porém, foi utilizado um protocolo de longa duração, sendo que aplicações de crioterapia acima de 2 horas consecutivas podem aumentar a lesão por hipóxia secundária (56). Um estudo anterior propôs a aplicação de 
crioterapia durante 6 horas consecutivas após lesão do músculo TA em ratos e evidenciou uma redução do infiltrado de neutrófilos, granulócitos e macrófagos na lesão e uma redução da área de lesão secundária (26). Apesar desses estudos trazerem grandes contribuições para a área básica, os mesmos não apresentam foco clínico, e não abordam a aplicação intermitente da crioterapia como é realizada na prática da fisioterapia. Assim, já em 2007, o grupo de pesquisa do Prof. Vogt (Hannover, Germany) escreveu uma carta ao editor da The American Journal of Sports Medicine mostrando preocupação com esse tema da aplicabilidade clínica das pesquisas (57).

É questionável se a redução da temperatura e metabolismo tecidual, que teoricamente está associada a redução do processo inflamatório e o dano oxidativo, poderá, por outro lado, prejudicar o reparo tecidual, uma vez que o processo inflamatório desencadeia a cascata de reparo tecidual. Takagi e colaboradores (2011) estudaram o efeito de uma única sessão de crioterapia aplicada com saco de gelo durante 20 minutos imediatamente após a lesão muscular do extensor longo dos dedos em ratos. Os resultados demonstraram que a crioterapia retardou em aproximadamente um dia a degeneração das fibras musculoesqueléticas necróticas e diferenciação das células satélites nos estágios iniciais de regeneração, bem como reduziu o número de macrófagos. A crioterapia também aumentou a proporção de fibras em regeneração que mostram núcleo centralizado 14 dias após a lesão e a área da secção transversa das fibras musculoesqueléticas foi reduzida após 28 dias da lesão. Assim, os autores concluíram que o protocolo de crioterapia utilizado reduziu a resposta inflamatória que pode estar associada ao retardo da regeneração muscular e aumento do conteúdo do colágeno. Em contrapartida, há de se considerar que o processo inflamatório exacerbado pode ser nocivo ocasionando, por exemplo, fibroses (59).

Com relação ao tempo de tratamento, é reconhecido que o tempo de aplicação deve ser em torno de 20 a 30 minutos, sem efeito adicional quando a duração da aplicação é superior a esse período (16-19). Quanto à duração do tratamento, sugere-se que nas lesões agudas a crioterapia seja aplicada nas primeiras 72 horas $(16,32,60-62)$, respeitando a primeira fase do processo de regeneração muscular correspondente à destruição e inflamação. Desse modo, o protocolo de tratamento da crioterapia escolhido para estudo foi de três aplicações de 30 minutos, diariamente, nas primeiras 72 horas após a lesão muscular, com objetivo de mimetizar o recomendado na prática clínica (16).

Até onde sabemos nenhum estudo investigou os efeitos de um protocolo de crioterapia segundo as recomendações da prática clínica, sobre o estresse oxidativo. 0 presente estudo pretende investigar o efeito de aplicações intermitentes de crioterapia, nas primeiras 72 horas após criolesão de músculo TA em ratos, sobre o infiltrado inflamatório e o dano oxidativo, ao longo de 14 dias. Dessa forma, os resultados desse estudo fornecerão subsídios científicos ao uso clínico dos protocolos intermitentes de crioterapia no tratamento de lesão musculoesquelética aguda. Baseado nos aspectos teóricos e nos achados prévios da literatura, a hipótese desse estudo é que seguindo as recomendações clínicas de aplicação intermitente da crioterapia nas primeiras 72 horas após a lesão muscular, essa 
estratégia terapêutica poderá minimizar o infiltrado inflamatório e o dano oxidativo após criolesão em TA de ratos. 
3.OBJETIVOS

\subsection{Objetivo geral}

Analisar o efeito de aplicações intermitentes de crioterapia, nas primeiras 72 horas após lesão do músculo TA em ratos, sobre o infiltrado inflamatório e o dano oxidativo ao longo de 14 dias.

\subsection{Objetivos específicos}

- Verificar se o efeito de aplicações intermitentes de crioterapia, nas primeiras 72 horas após lesão musculoesquelética em ratos, influencia a densidade do infiltrado inflamatório.

- Verificar se o efeito de aplicações intermitentes de crioterapia, nas primeiras 72 horas após lesão musculoesquelética influencia a produção de marcadores indiretos de dano oxidativo.

- Verificar se o efeito de aplicações intermitentes de crioterapia, nas primeiras 72 horas após lesão musculoesquelética influencia a viabilidade celular.

- Verificar se o efeito aplicações intermitentes de crioterapia, nas primeiras 72 horas após lesão musculoesquelética em ratos, influencia o sistema de defesa antioxidante. 


\section{MATERIAIS E MÉTODOS}

\subsection{Animais}

No presente estudo, foram utilizados 35 ratos da linhagem Wistar, adultos, com peso médio de $301.8 \pm 17.6 \mathrm{~g}$. Os animais foram agrupados em gaiolas plásticas com livre acesso à água e ração peletizada, com controle de luminosidade (ciclo claro/escuro de 12h) e com temperatura controlada (Socil, São Paulo). Os experimentos foram conduzidos seguindo as recomendações éticas do Guide for Care and Use of Laboratory Animals (National Research Council, 1996), sendo que o projeto de pesquisa foi aprovado no Comitê de Ética em Experimentação Animal (Protocolo no 059/2010 - Anexo I). Todos os procedimentos experimentais foram realizados com os animais anestesiados com (injeção intraperitonial de solução de xylazina $12 \mathrm{mg} / \mathrm{kg} /$ peso corporal e ketamina $95 \mathrm{mg} / \mathrm{kg} / \mathrm{peso}$ corporal). Os animais foram eutanasiados por overdose anestésica, no período de análise de cada grupo experimental.

\subsection{Grupos experimentais}

$O$ efeito da crioterapia sobre o processo inflamatório e sobre o dano oxidativo foi analisado em três períodos: 3,7 e 14 dias após a lesão do músculo TA dos animais. Os ratos foram distribuídos aleatoriamente em sete grupos experimentar com cinco animais cada: (1) controle (C), animais sem intervenção; (2) grupo lesão não tratado, analisado 3 dias após a lesão (L3); (3) grupo lesão tratado com crioterapia, analisado 3 dias após a lesão (L3+C); (4) grupo lesão não tratado, analisado 7 dias após a lesão (L7); (5) grupo lesão tratado com crioterapia, analisado 7 dias após a lesão $(L 7+C)$; $(6)$ grupo lesão não tratado, analisado 14 dias após a lesão (L14); (7) grupo lesão tratado com crioterapia, analisado 14 dias após a lesão (L14+C) (Figura 1).

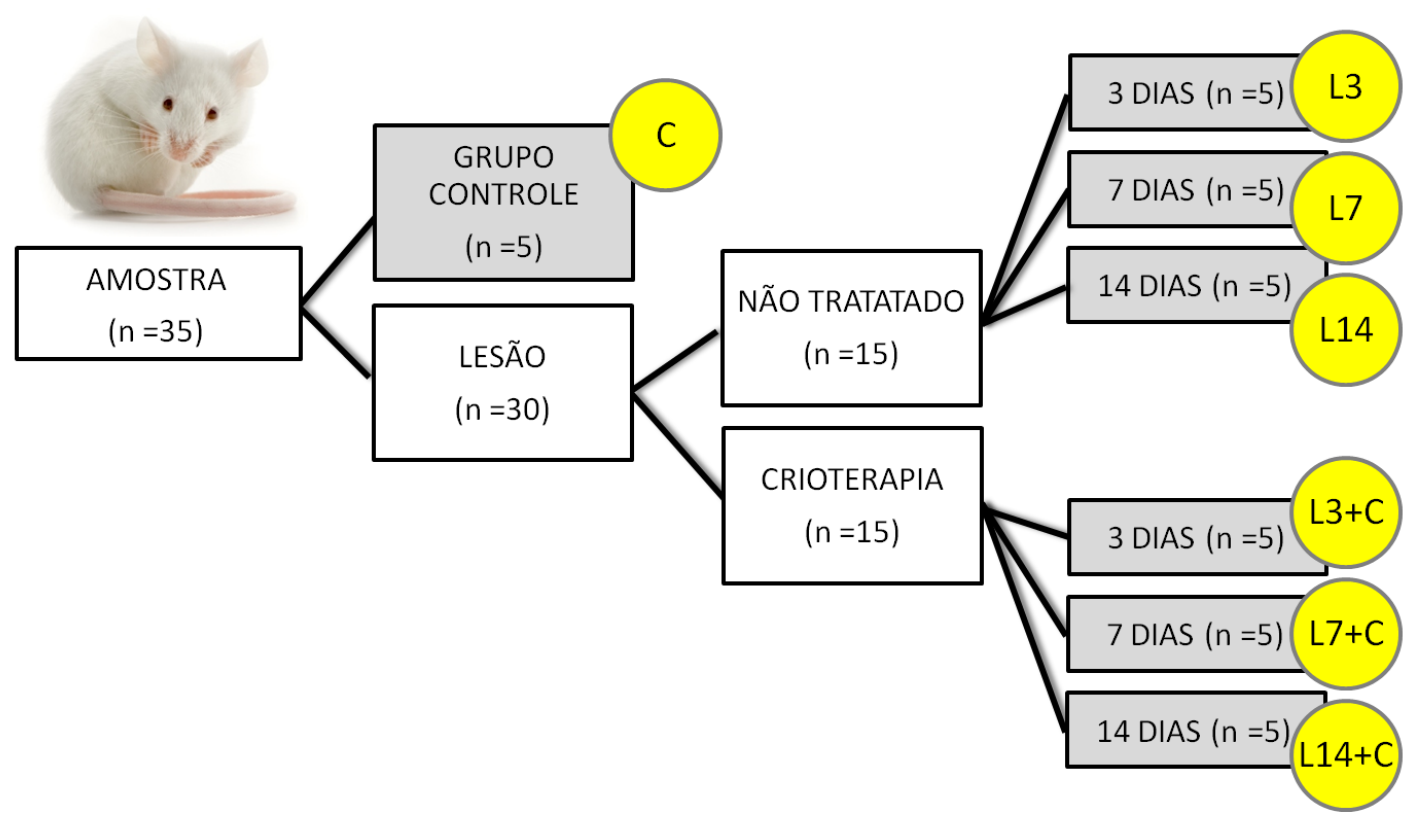

Figura 1 - Desenho dos grupos experimentais. 


\subsection{Protocolo de lesão muscular}

Os animais foram anestesiados para o procedimento cirúrgico que induziu a lesão muscular e então, a pele que recobre o músculo TA direito foi tricotomizada e limpa com álcool iodado. Em seguida, foi realizada uma incisão transversal, de aproximadamente 1 $\mathrm{cm}$, na região correspondente ao ventre do músculo. Para completa exposição do ventre TA direito, a fáscia que o recobre foi seccionada e afastada (Figura 2A).

A lesão muscular foi induzida por congelamento (criolesão) na região central do ventre do músculo TA, conforme previamente descrito $(10,13,63)$. Resumidamente, um bastão de ferro $\left(40 \times 20 \mathrm{~mm}^{2}\right)$, previamente imerso e congelado em nitrogênio líquido, foi posicionado transversalmente sobre 0 ventre do músculo por 10 segundos. Esse procedimento foi repetido mais duas vezes com o intervalo de 30s entre eles (Figura 2B-C). Em seguida, a pele foi suturada (Fio Nylon 3-0 - Shalon LTDA) e limpa com álcool iodado (Figura 2D).

A lesão foi realizada na porção mais larga do ventre do TA, identificado com auxílio de um paquímetro. Estudos prévios demonstraram que esse procedimento acarreta um sítio de lesão bastante homogêneo e restrito à região superficial do ventre do músculo TA em ratos, sendo um bom modelo para avaliação da lesão e regeneração muscular. O músculo TA foi escolhido por apresentar o ventre localizado superficialmente na região anterior da pata do animal, com fácil acesso cirúrgico $(10,63)$.
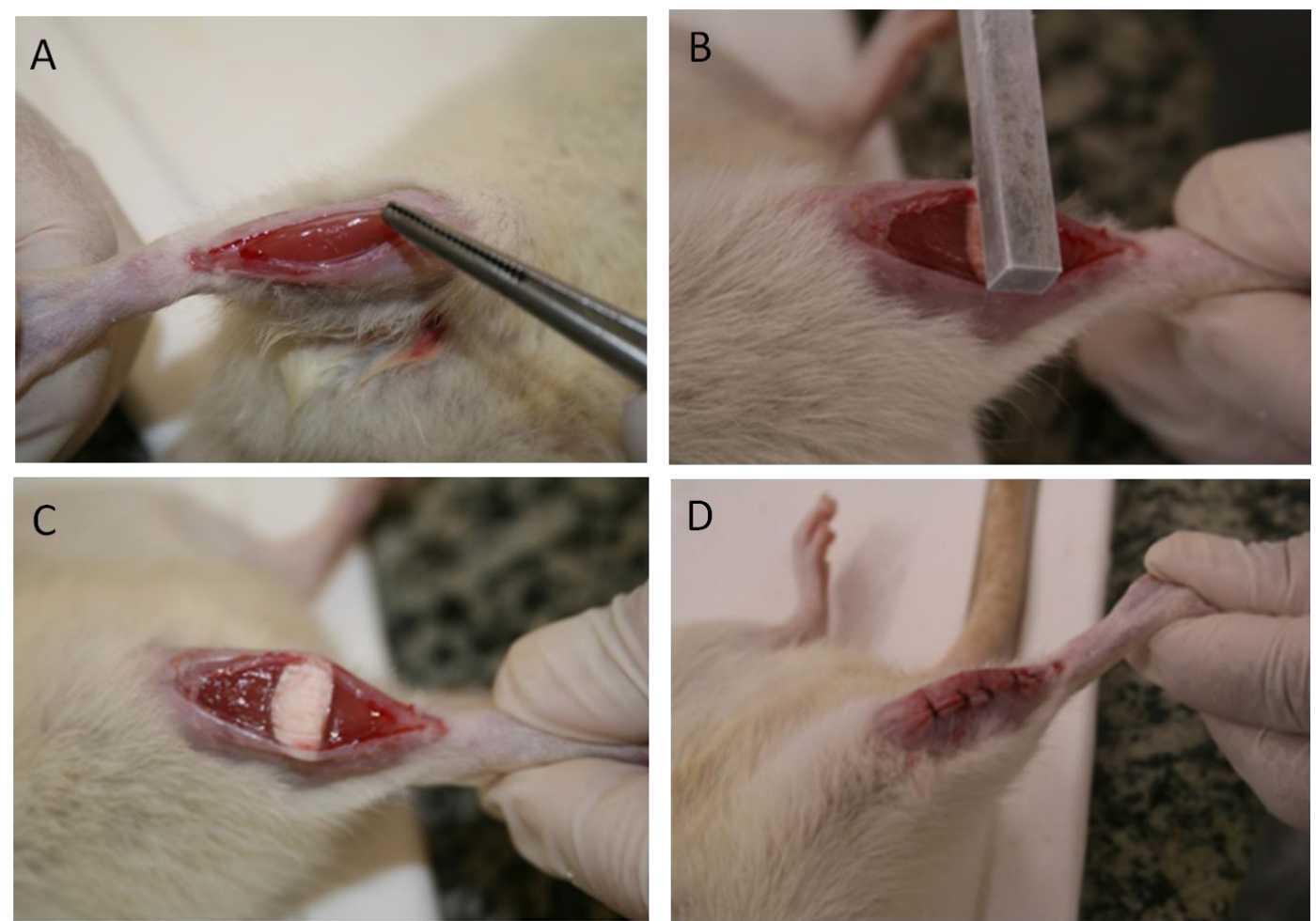

Figura 2 - Esquema ilustrativo da criolesão no ventre do músculo TA. 


\subsection{Protocolo de crioterapia}

Após a indução da lesão muscular, sutura e limpeza da pele, os animais, ainda sob efeito dos anestésicos, foram colocados em gaiolas de contenção na posição horizontal de modo que a pata direita permanecesse fixa, por meio de fita crepe, a uma plataforma de madeira para a posterior aplicação de crioterapia. A pata direita foi mantida na posição horizontal, mantendo os metatarsos dos animais presos à plataforma de madeira.

A técnica de crioterapia consistiu na aplicação de gelo triturado em saco plástico, o qual foi fixado com fita crepe diretamente sobre a pele da face anterior da pata direita do animal, cobrindo toda a região superficial do TA. Na colocação do saco de gelo sobre a pele, era realizada uma compressão com fita crepe, a qual foi fixada sempre pela mesma pessoa a fim de evitar compressões diferenciadas (10,54). O protocolo de crioterapia consistiu de 3 sessões crioterapia nas primeiras 72 horas, sendo a primeira sessão iniciada imediatamente após a lesão do TA, a segunda 24 horas após a lesão do TA e a terceira 48 horas após a lesão do TA . Cada sessão correspondeu a três aplicações de crioterapia com 2 horas de intervalo entre elas. Cada aplicação teve duração de 30 minutos. Dessa forma, totalizaram. 9 aplicacões de crioterapia nas primeiras 72 horas após a lesão do TA. (Figura 3). Todas as sessões foram realizadas com os animais anestesiados.

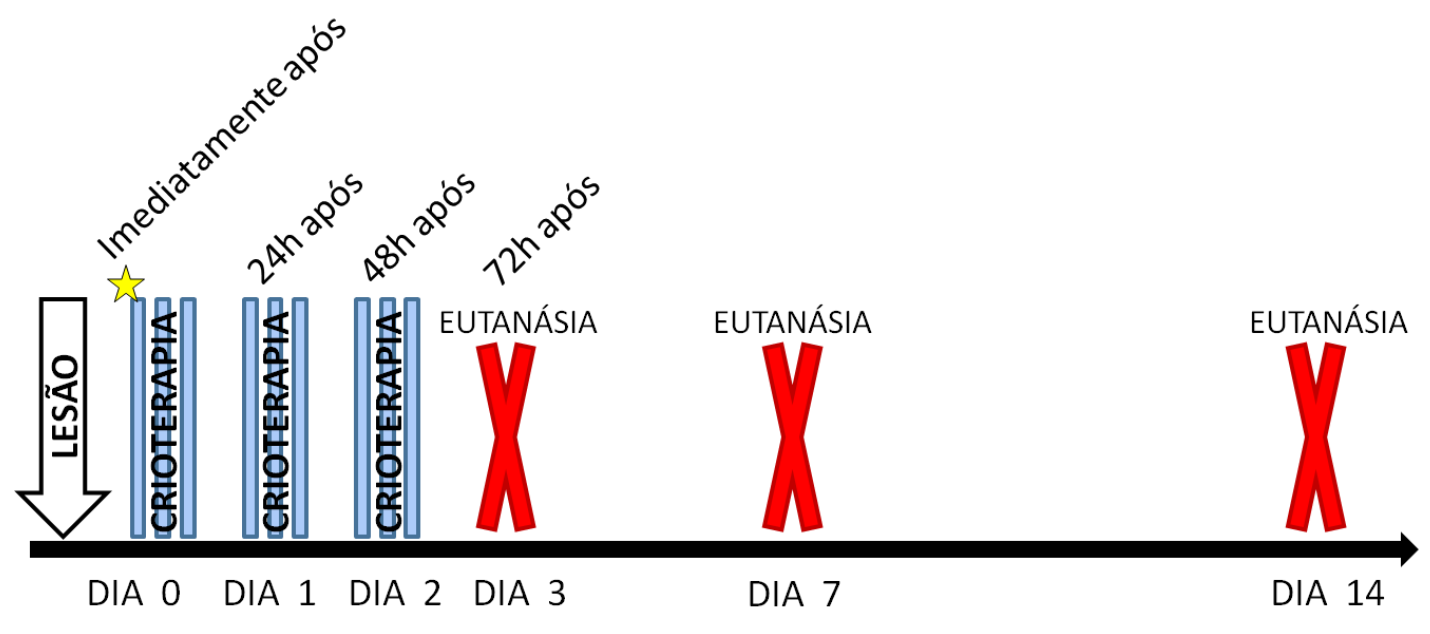

TEMPO APÓS A LESÃO (DIAS)

Figura 3 - Desenho experimental do estudo.

\subsection{Retirada dos músculos}

No período de análise de cada grupo, os respectivos animais foram eutanasiados com overdose anestésica (Figura 3). Os músculos TA direito de todos os animais foram dissecados e retirados. Após a retirada, os músculos foram divididos em duas porções similares, com um corte horizontal no seu ventre. Uma porção (proximal) foi utilizada para a análise histológica, e a outra (distal) foi utilizada para análise bioquímica. 


\section{6 Área da lesão muscular}

Para as análises histológicas, a porção proximal do músculo TA direito de cada animal foi imediatamente congelada em isopentano (pré-congeladas em nitrogênio líquido) e armazenada em freezer a $-80^{\circ} \mathrm{C}$ (Forma Scientific, Marietta, Ohio). Foram obtidos cortes histológicos transversais e seriados (uma seção de $10 \mu \mathrm{m}$ a cada $100 \mu \mathrm{m}$ ) em micrótomo criostato (Microm HE 505, Jena, Alemanha), ao longo do ventre do músculo TA de cada grupo. As lâminas com os cortes histológicos foram coradas com azul de Toluidina para avaliação por meio de microscopia óptica (Axiolab, Carl Zeiss, Alemanha). Foi escolhido um corte transversal de cada músculo localizado na região mais central da lesão muscular para medir a área de secção transversal do músculo lesado nos grupos tratados e não tratados, utilizando um software de morfometria (Axiovision 3.0.6 SP4, Carl Zeiss, Alemanha). Para tal, fotos da secção transversal dos músculos foram obtidos por microscopia óptica para reconstruir a área de secção transversal total, o que permitiu identificar e medir as áreas intactas e lesadas de cada músculo. Para a análise quantitativa da área de inflamação, foi utilizado o microscópio óptico (Axiocam, Carl Zeiss, Jena, Germany) com ampliação final de 40x, com as definições mantidas para todos os cortes. A quantificação da área de infiltrado inflamatório foi realizada usando o software ImageJ (version 1.41; Wayne Rasband, National Institutes of Health, Bethesda, MA, USA).

Para a análise qualitativa da área de inflamação após a lesão muscular, foram escolhidos seis cortes histológicos da área de secção transversal do TA de diferentes animais, um corte representativo de cada período entre os animais dos grupos lesão não tratados e tratados. A análise qualitativa dos cortes incluiu a descrição das fases de regeneração do tecido musculoesquelético, envolvendo a presença de fibras necróticas, infiltrado inflamatório, fibras musculares em fase de regeneração (núcleo centralizado) e fibras basofílicas.

\subsection{Análise bioquímica do músculo esquelético homogeneizado}

A análise bioquímica foi realizada para avaliação de alterações indicativas de dano oxidativo e da resposta de defesa antioxidante. Os grupos lesão não tratados e tratados foram avaliados em três períodos: 3,7 e 14 dias após a lesão do músculo TA. O grupo controle foi avaliado no mesmo período dos grupos analisados três dias após a lesão.

Para a análise bioquímica, o fragmento distal do músculo TA foi prontamente homogenizado em $\mathrm{NaCl}(150 \mathrm{nM})$ e centrifugado a 4.000 girus por 10 minutos a $4^{\circ} \mathrm{C}$ durante para obter-se a fração de sobrenadante de baixa velocidade. A amostra da fração de sobrenadante de baixa velocidade foi usada para determinar: os níveis de DCF-RS, TBARS, redução do MTT e -SH não-proteicos; além das atividades enzimáticas da CAT e SOD.

\subsection{Determinação dos marcadores de dano oxidativo e da viabilidade celular}

4.8.1 Níveis de diclorofluoresceína oxidada 
A análise dos níveis de DCF-RS é utilizada como um índice da formação de espécies reativas tais como peróxidos celulares (64). A formação excessiva de espécies reativas em uma situação de dano oxidativo pode ser analisada a partir da reação das mesmas com o composto diclorofluoresceína, e assim promover a sua oxidação na forma altamente fluorescente DCF-RS (65).

O procedimento experimental foi realizado de acordo com o método proposto por Pérez-Severiano e colaboradores (2004), com algumas modificações. As análises foram realizadas utilizando-se de alíquotas de fração de sobrenadante de baixa velocidade $(50 \mu \mathrm{L})$ das amostras do tecido muscular encubadas em um meio de reação contendo Tris- $\mathrm{HCl}$

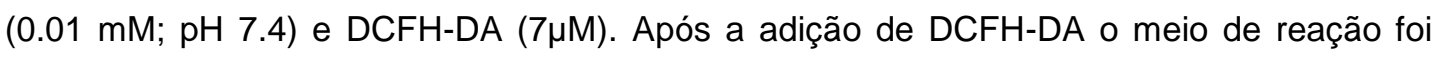
encubado no escuro por um período de 1 hora até a realização do procedimento de quantificação da fluorescência da DCF-RS (excitação: $488 \mathrm{~nm}$, emissão: $525 \mathrm{~nm}$, e ambas as aberturas do feixe de luz a $5 \mathrm{~nm}$ ). Os resultados foram corrigidos pela quantidade de proteínas e expressos em nmol de DCF-RS por miligrama de proteína.

\subsubsection{Níveis de substâncias reativas ao ácido tiobarbitúrico}

A análise dos níveis de TBARS é utilizada como um índice do dano oxidativo aos lipídios de membrana durante um processo denominado de peroxidação lipídica. Os produtos finais do comprometimento das membranas celulares, tal como o malondialdeído (MDA), podem reagir com o TBA e resultar na formação de complexos coloridos, os quais possuem um coeficiente de absorção máxima em 532 nanômetros (nm) (Ohkawa et al., 1979).

As análises foram realizadas em alíquotas de fração de sobrenadante de baixa velocidade $(200 \mu \mathrm{L})$ das amostras do tecido muscular. As amostras foram submetidas à reação e a análise colorimétrica segundo o método proposto por Ohkawa e colaboradores (1979). Os resultados foram calculados em nmol de MDA com relação aos valores de TBARS encontrados em concentrações conhecidas de MDA utilizado como padrão, corrigidos pela quantidade de proteínas, e expressos em nmol de MDA por miligrama de proteína.

\subsubsection{Níveis de redução do metil-tiazol-tetrazólio}

A análise da redução do MTT pode ser utilizada como um índice da funcionalidade de enzimas desidrogenases, as quais são fundamentais na catalisação de reações bioquímicas envolvidas na obtenção de energia intracelular (43). Desta forma, os procedimentos experimentais de análise da redução do MTT podem ser utilizados como um possível indicador da viabilidade celular nas amostras testadas (68). Em condições funcionais adequadas as enzimas desidrogenases reduzem o MTT a formazan, o qual pode ser determinado espectrofotometricamente a 570nm (69).

O procedimento experimental foi realizado de acordo com o método proposto por Mosmann (1983), com algumas modificações. Os níveis de redução do MTT foram 
investigados utilizando-se de alíquotas de fração de sobrenadante de baixa velocidade $(500 \mu \mathrm{L})$ das amostras do tecido muscular. As amostras foram encubadas no escuro em um meio de reação contendo $0.5 \mathrm{mg} / \mathrm{mL}$ de $\mathrm{MTT}$ à $37^{\circ} \mathrm{C}$ por 1 hora. A reação foi finalizada com a adição do solvente dimetil sulfóxido $(1 \mathrm{~mL})$, e posteriormente submetidas a análise espectrofotométrica. Os resultados foram corrigidos pela quantidade de proteínas e expressos em porcentagem do grupo controle.

\subsection{Determinação da resposta de defesa antioxidante}

\subsubsection{Atividade da enzima superóxido dismutase}

A análise da atividade da enzima SOD também é utilizada como um índice da funcionalidade de um dos sistemas antioxidantes de origem enzimática envolvidos na neutralização de espécies reativas prejudiciais ao organismo. A SOD catalisa a reação do radical livre $\mathrm{O}_{2}^{-}$com uma molécula de água $\left(\mathrm{H}_{2} \mathrm{O}\right)$, e assim a sua dismutação em $\mathrm{H}_{2} \mathrm{O}_{2}(65)$.

$A$ atividade da SOD foi determinada espectrofotometricamente em amostras do tecido muscular, segundo o método proposto por Misra e Fridovich (1972), o qual está embasado na capacidade da SOD em inibir a auto-oxidação da adrenalina em adenocromo, com algumas modificações. As análises foram realizadas utilizando-se de alíquotas de fração de sobrenadante de baixa velocidade das amostras do tecido muscular, as quais foram adicionadas em um meio de reação contendo tampão glicina (50mM; pH 10.5) e adrenalina $(1 \mathrm{mM})$. A análise cinética da atividade da SOD foi iniciada a partir da adição de adrenalina, e a reação foi monitorada a $480 \mathrm{~nm}$ até o momento em que a máxima degradação da adrenalina for observada. Os resultados foram calculados em unidades de SOD por litro (U/L), corrigidos pela quantidade de proteínas e expressos em unidades de SOD por miligrama de proteína.

\subsubsection{Atividade da enzima catalase}

A análise da atividade da CAT é utilizada como um índice da funcionalidade de um dos sistemas antioxidantes de origem enzimática mais importante na neutralização de espécies reativas prejudiciais ao organismo. A CAT catalisa a reação de degradação do $\mathrm{H}_{2} \mathrm{O}_{2}$ em moléculas $\mathrm{H}_{2} \mathrm{O}$ (65).

A atividade da CAT foi determinada espectrofotometricamente em amostras do tecido muscular, segundo o método proposto por Aebi (1984), o qual está embasado na capacidade da CAT em degradar $\mathrm{H}_{2} \mathrm{O}_{2}$, com algumas modificações. As análises foram realizadas utilizando-se de alíquotas de fração de sobrenadante de baixa velocidade das amostras do tecido muscular $(50 \mu \mathrm{L})$, as quais foram adicionadas em um meio de reação contendo tampão fosfato de potássio $(50 \mathrm{mM} ; \mathrm{pH} 7.4)$ e $\mathrm{H}_{2} \mathrm{O}_{2}(1 \mathrm{mM})$. A análise cinética da atividade da CAT foi iniciada a partir da adição de $\mathrm{H}_{2} \mathrm{O}_{2}$, e a reação foi monitorada a 240nm por 2 minutos. Os resultados foram calculados e corrigidos pela quantidade de proteínas e expresso em nmol $\mathrm{H}_{2} \mathrm{O}_{2} / \mathrm{min} / \mathrm{mg}$ de proteína. 


\subsubsection{Níveis de grupos tióis não-proteicos}

A análise dos níveis de grupos -SH não-proteicos podem ser utilizados como um indicador do principal sistema de defesa antioxidante endógeno, de atuação não enzimática, da GSH. A GSH depende da integridade do grupo -SH em seu resíduo de cisteína para exercer a sua capacidade de neutralizar as espécies reativas, e assim limitar o dano oxidativo aos tecidos biológicos $(72,73)$.

O procedimento experimental para a determinação dos grupos -SH não-proteicos foi desenvolvido de acordo com o método proposto por Ellman (1952), o qual baseia-se na reação dos grupos -SH com o ácido 5,5-ditiobis(2-nitrobenzóico) (DTNB) utilizado como reagente de cor, com algumas modificações (74).

Os níveis de grupos -SH não-proteicos foram determinados após a precipitação do conteúdo proteico das amostras pela adição de uma alíquota de TCA 5\% (1mL) em uma alíquota de fração de sobrenadante de baixa velocidade $(500 \mu \mathrm{L})$ das amostras do tecido muscular. O conteúdo precipitado foi então centrifugado a 4.000 girus por 10 minutos, e uma alíquota do sobrenadante $(500 \mu \mathrm{L})$ foi utilizada na reação colorimétrica. A reação colorimétrica foi desenvolvida mediante a adição das alíquotas a serem testadas em um meio contendo tampão fosfato de potássio $(0.25 \mathrm{mM}$; pH 7.4$)$ e DTNB $(1 \mathrm{mM})$. A análise colorimétrica foi desenvolvida espectrofotometricamente a $412 \mathrm{~nm}$ após 30 minutos da adição do DTNB, e o conteúdo de grupos -SH foi calculado com relação aos valores encontrados em concentrações conhecidas de GSH utilizadas como padrão. Os resultados foram corrigidos pela quantidade de proteínas e expressos em nmol de - SH por miligrama de proteína.

\subsection{Determinação das proteínas}

O conteúdo de proteínas foi determinado de acordo com Lowry e colaboradores (1951) usando albumina do soro bovino (BSA) como proteína padrão (75).

\subsection{Análise estatística}

Os dados foram apresentados de maneira descritiva: média e desvio padrão $( \pm D P)$. Os níveis de MTT reduzido foram calculados como porcentagem do grupo controle. A normalidade e homogeneidade dos dados foram verificadas pelos testes de Shapiro-Wilk e Levene, respectivamente. A diferença entre os grupos em relação a cada variável foi comparada pela análise de variância (ANOVA) de dois fatores, seguida pelo teste de Tukey. Para todas as análises, um valor de $p$ igual ou menor que 0.05 foi aceito como estatisticamente significante. Os dados foram analisados com o Statistical Package for Social Sciences (SPSS, v21.0). 


\section{RESULTADOS}

\subsection{Histologia da regeneração muscular e quantificação do infiltrado inflamatório}

Comparativamente ao grupo controle, a densidade de infiltrado inflamatório aumentou nos grupos lesão não tratados e tratados em todos os períodos analisados (L3: 5.7 vezes; $L 3+C$ : 5.0 vezes; L7: 3.5 vezes; $L 7+C$ : 2.7 vezes; $L 14: 2.0$; $L 14+C$ : 1.9 vezes, $\mathrm{p}<0.001$ para todos; Figura $4 \mathrm{G}$ ). Por outro lado, foi observada uma redução da densidade de infiltrado inflamatório, nos dias 3 e 7 após a lesão, nos grupos tratados, quando comparado aos grupos lesão não tratado nos mesmos períodos $(L 3+C$ : 0.9 vezes, $p=0.002$; L7+C: 0.8 vezes, $p<0.001$; Figura 4A-D e G). Comparando-se o dia 7 com o dia 3 após a lesão, foi observada uma menor densidade de infiltrado inflamatório intragrupos lesão não tratado e tratado (L7: 0.6 vezes, $p<0.001$; $L 7+C$ : 0.5 vezes, $p<0.001$; Figura $4 A-D$ e $G$ ). Além disso, no dia 7 após a lesão, tanto nos grupos lesão não tratado quanto no tratado puderam-se observar fibras musculares em intenso processo de regeneração devido à presença de núcleo centralizado e fibras basofílicas, caracterizando atividade ribossômica. Contudo, no dia 14 após a lesão, a crioterapia não modificou a densidade de infiltrado inflamatório no grupo tratado quando comparado ao grupo lesão não tratado (L14+C: 1.0 vezes, $\mathrm{p}=1.0$; Figura $4 \mathrm{E}-\mathrm{G})$.

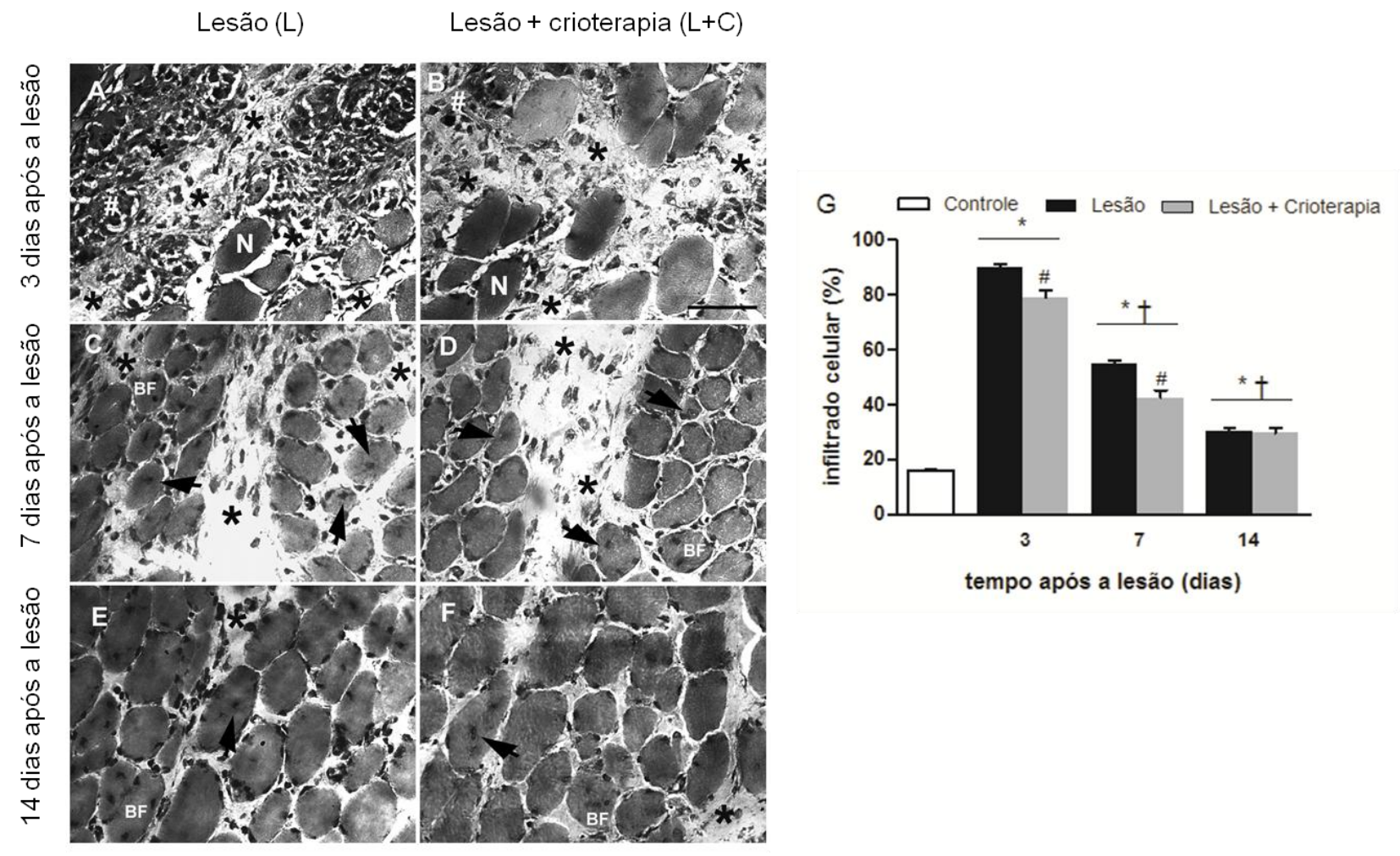

Figura 4 - Fotomicrografia de cortes transversais de músculo TA de ratos, corados com azul de Toluidina, dos grupos lesão não tratados e tratados com crioterapia, avaliados nos dias 3, 7 e 14 após lesão musculoesquelética. (A) Músculo do grupo lesão não tratado, avaliado 3 dias após lesão (L3) - notar a presença de fibras musculares necróticas (\#) e a intensa presença de infiltrado inflamatório (*). (B) Músculo do grupo lesão tratado, avaliado 3 dias 
após lesão $(\mathrm{L} 3+\mathrm{C})$ - diminuição da presença de infiltrado inflamatório em relação a L3. (C) Músculo do grupo lesão não tratado, avaliado 7 dias após a lesão - fibras musculares em intenso processo de regeneração, caracterizado pela núcleo centralizado (setas) e fibras basofílicas com núcleo proeminente (BF). Além de uma menor presença de infiltrado inflamatório em relação ao L3. (D) Músculo do grupo lesão tratado, avaliado 7 dias após a lesão fibras musculares em intenso processo de regeneração e infiltrado inflamatório reduzido em relação a L7. (E e F). Respectivamente, os músculos do grupo lesão não tratado (L14) e tratado $(L 14+C)$, avaliado 14 dias após a lesão - o processo de regeneração persiste, com uma mínima presença de infiltrado inflamatório, diferentemente de dos grupos avaliados $3(L 3, L 3+C)$ e $7(L 7$ e $L 7+C)$ dias após a lesão. Notar que 14 dias após a lesão não há diferença entre os grupos não tratado e tratado, indicado um processo regenerativo similar. (400x). Bar: 50um. (G) Porcentagem de infiltrado inflamatório no músculo TA de ratos. Os dados estão expressos como média e $\pm \mathrm{DV}$. * diferença quando comparado ao grupo controle $(p<0.05)$; \# diferença entre os grupos $(p<0.05)$; $\dagger$ diferença entre $o$ período de 3 dias após a lesão $(p<0.05)$.

\subsection{Dano oxidativo e viabilidade celular}

A análise dos níveis de DCF-RS no grupo controle permitiu-nos observar que 0 mecanismo de criolesão aumentou os níveis de DCF-RS nos grupos lesão não tratados a partir do dia 7 após a lesão (L7: 7.5 vezes, $p<0.001$; L14: 9.0 vezes, $p<0.001$; Figura 5A). Entretanto, a crioterapia evitou o aumento dos níveis de DCF-RS nos grupos lesão tratados, nos dias 7 e 14 após a lesão, quando comparado aos grupos não tratados ( $L 7+C$ : 0.1 vezes, $p<0.001$; L14+C: 0.3 vezes; $p<0.001$; Figura $5 A$ ).

Os níveis de TBARS nos grupos lesão não tratados apresentaram um aumento tanto no dia 3, quanto no dia 7 após a lesão, quando comparados ao grupo controle (L3: 2.8 vezes, $p<0.001$; L7: 2.3 vezes, $p=0.022$; Figura $5 B$ ). Interessantemente, nos mesmos períodos, a crioterapia evitou o aumento dos níveis de TBARS nos grupos lesão tratados quando comparado aos grupos lesão não tratados ( $L 3+C$ : 0.4 vezes, $p=0.002$; $L 7+C$ : 0.5 vezes, $\mathrm{p}=0.032$; Figura $5 \mathrm{~B}$ ).

No dia 3 após a lesão, o grupo lesão não tratado apresentou uma diminuição no nível de MTT reduzido comparativamente ao grupo controle (L3: 0.5 vezes; $p=0.023$; Figura 5C). Contudo, a crioterapia evitou a diminuição dos níveis de MTT reduzido em todos os períodos nos grupos tratados, quando comparado aos respectivos grupos lesão não tratados $(L 3+C: 2.2$ vezes, $p=0.002 ; L 7+C: 1.7$ vezes, $p=0.044$; $L 14+C: 1.7$ vezes, $p=0.035$; Figura $5 \mathrm{C})$. 

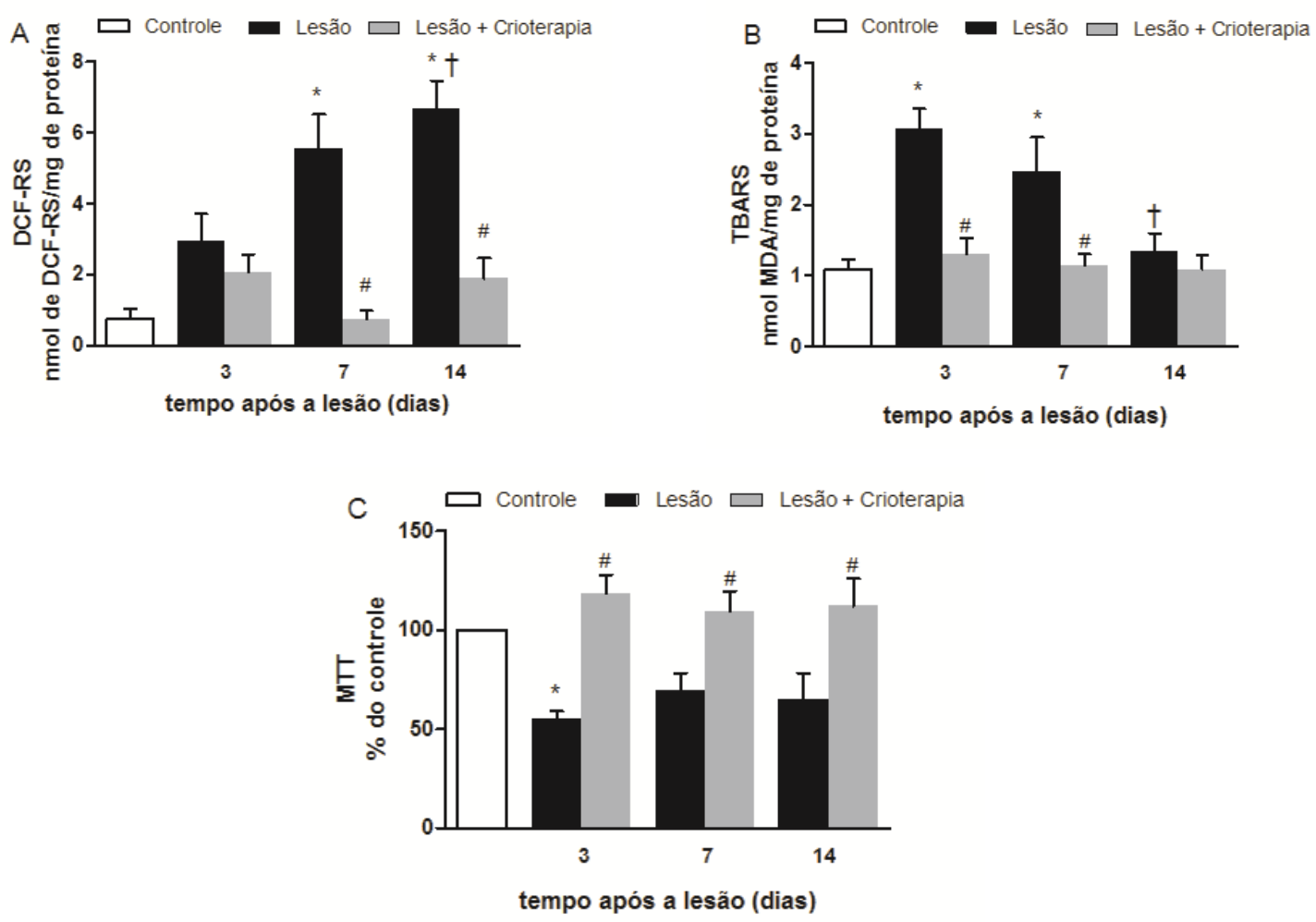

Figura 5 - Efeitos de aplicações intermitentes de crioterapia nas primeiras 72 horas após a lesão do músculo TA sobre o dano oxidativo: (A) níveis de diclorofluoresceína oxidada (DCF-RS), expressos em nmol de DCF-RS/mg de proteína; (B) níveis de substâncias reativas ao ácido tiobarbitúrico (TBARS), expressos em nmol de malondialdeído (MDA)/mg de proteína; (C) níveis de redução do metil-tiazol-tetrazólio (MTT), expressos em porcentagem em relação ao valor do grupo controle. Os dados estão expressos como média \pm DP. * diferença quando comparado ao grupo controle $(p<0.05)$; \# diferença entre os grupos $(p<0.05)$; † diferença entre o período de 3 dias após a lesão $(p<0.05)$.

\subsection{Sistema antioxidante}

Comparativamente ao grupo controle, a atividade enzimática da SOD aumentou nos grupos lesão não tratados em todos os períodos analisados (L3: 2.2 vezes, $p=0,005 ;$ L7: 2.8 vezes, $\mathrm{p}<0.001$; L14: 2.8 vezes, $\mathrm{p}<0.001$; Figura $6 \mathrm{~A}$ ). Contudo, nos dias 7 e 14 após a lesão, a crioterapia evitou o aumento da atividade enzimática da SOD nos grupos tratados quando comparado aos grupos não tratados $(L 7+C$ : 0.5 vezes, $p=0.001$; $L 14+C$ : 0.6 vezes; $\mathrm{p}=0.008$; Figura $6 \mathrm{~A}$ ).

Apenas no dia 3 após a lesão, a atividade enzimática da CAT no grupo não tratado aumentou comparativamente ao grupo controle (L3: 3.4 vezes, $p<0.001$; Figura 6B). Interessantemente, no dia 3 , a crioterapia manteve baixa a atividade enzimática da CAT no grupo tratado, quando comparado ao respectivo grupo lesão não tratado ( $L 3+C$ : 0.2 vezes, $\mathrm{p}<0.001$; Figura 6B).

Comparativamente ao grupo controle, no dia 3 após a lesão, os níveis de grupos SH não-proteicos apresentaram uma diminuição significativa no grupo lesão não tratado (L3: 0.5 vezes; $p=0.015$; Figura $6 \mathrm{C}$ ). Por outro lado, no mesmo período, a crioterapia manteve o nível de grupos -SH não-proteicos no grupo tratado similares aos do grupo 
controle ( $\mathrm{L} 3+\mathrm{C}: \mathrm{p}=0.920$; Figura $6 \mathrm{C}$ ), porém sem diferença significativa quando comparado ao grupo não tratado (L3+C: 2.1 vezes, $p=0.174$, Figura $6 C$ ).
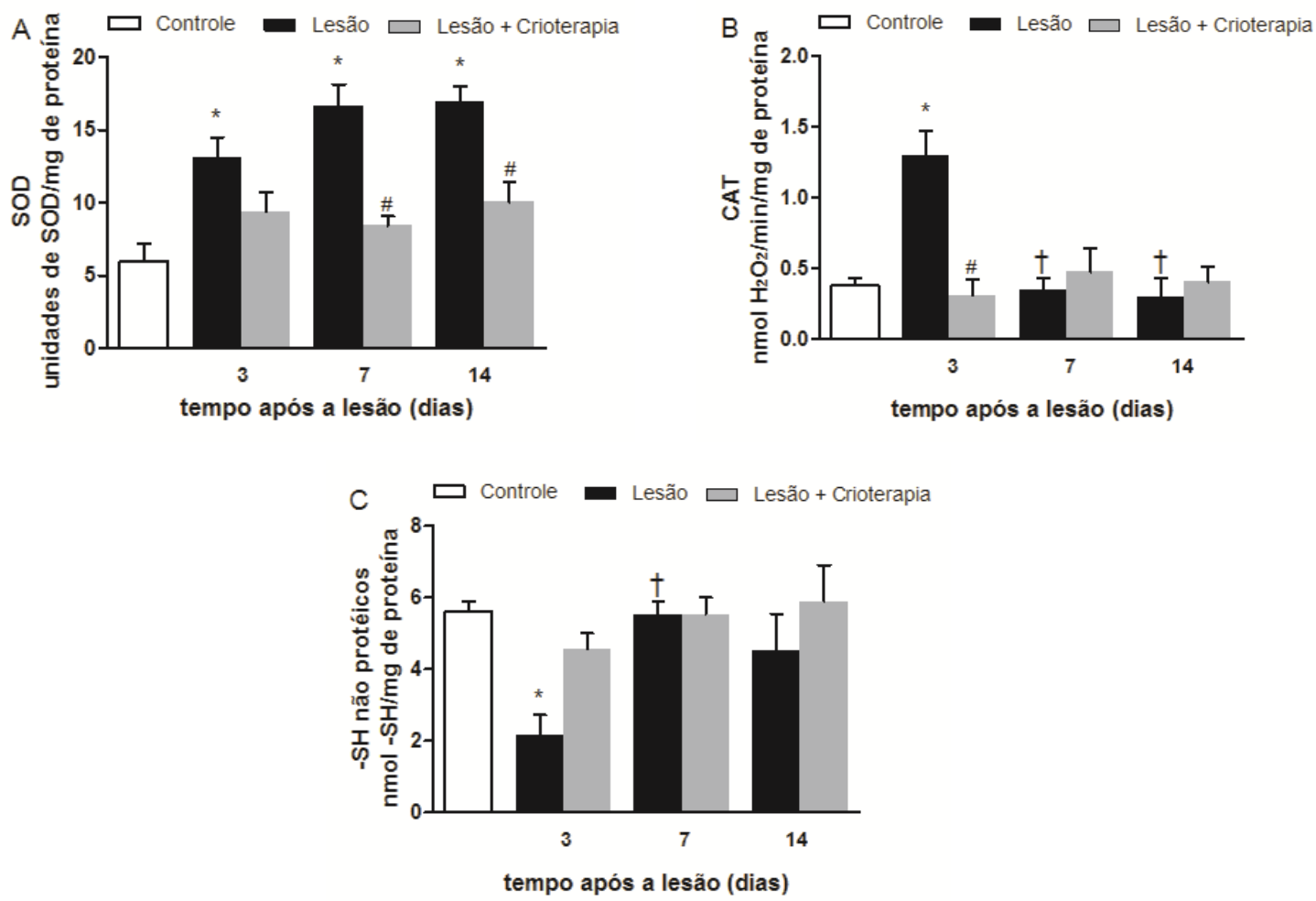

Figura 6 - Efeitos de aplicações intermitentes de crioterapia nas primeiras 72 horas após a lesão do músculo TA sobre a resposta antioxidante: (A) atividade enzimática da superóxido dismutase (SOD), expressa em unidades de $\mathrm{SOD} / \mathrm{mg}$ de proteína; (B) atividade enzimática da catalase (CAT), expressa em nmol $\mathrm{H}_{2} \mathrm{O}_{2} / \mathrm{min} / \mathrm{mg}$ de proteína; (C) níveis de grupos de tióis (-SH) não-proteicos, expressos em nmol - $\mathrm{SH} / \mathrm{mg}$ de proteína. Os dados estão expressos como média \pm DP. * diferença quando comparado ao grupo controle $(p<0.05)$; \# diferença entre os grupos $(p<0.05)$; † diferença entre o período de 3 dias após a lesão $(p<0.05)$. 


\section{DISCUSSÃO}

O presente estudo foi realizado com o objetivo de avaliar o efeito de aplicações intermitentes de crioterapia nas primeiras 72 horas, após criolesão em músculo TA em ratos, sobre o infiltrado inflamatório e o dano oxidativo, ao longo de 14 dias. A hipótese inicial do estudo foi confirmada. Seguindo as recomendações clínicas de aplicação intermitente da crioterapia nas primeiras 72 horas após a lesão muscular, o infiltrado inflamatório e o dano oxidativo foram minimizados após criolesão em músculo TA de ratos. Nossos achados são importantes para a compreensão básica do estresse oxidativo no mecanismo de lesão e os efeitos da aplicação de um protocolo clínico de crioterapia sobre o dano oxidativo durante a regeneração muscular, dando suporte à decisão dos profissionais de saúde e do esporte a respeito desses protocolos.

No presente estudo, os grupos lesão tratados apresentaram menor densidade de infiltrado inflamatório nos dias 3 e 7 após a lesão, quando comparado aos grupos não tratados. Esses resultados sugerem que o processo inflamatório no grupo tratado com crioterapia foi menor e estão de acordo com estudos prévios $(26,32,76,77)$. A redução do infiltrado inflamatório e, consequentemente a prevenção do edema têm sido justificadas pelo mecanismo de vasocontrição induzida pela crioterapia $(16,32,78)$. Contudo, encontramos estudos que sugerem que a crioterapia não altera o diâmetro arteriolar $(26,79,80)$, mas aumenta o diâmetro venoso, possivelmente aumentando a reabsorção do edema $(26,80)$. Além disso, a crioterapia seria responsável por uma redução da permeabilidade microvascular observada pela redução da interação leucócito-endotélio (80).

Uma série de efeitos fisiológicos indesejáveis, tais como dor, edema, restrição de amplitude de movimento, redução da força e limitação do desempenho funcional têm sido associados à resposta inflamatória após lesão musculoesquelética $(16,81)$. Nesse contexto, não está completamente estabelecido se a redução da resposta inflamatória é benéfica ou prejudicial no processo de regeneração muscular, na intensidade dos efeitos fisiológicos supracitados e na velocidade de recuperação funcional após lesão musculoesquelética. No presente estudo, a redução do infiltrado inflamatório nos grupos lesão tratados não causou diferença no processo de regeneração em relação aos grupos não tratados. Mesmo considerando que as células inflamatórias, especialmente os macrófagos e as células $T$, são cruciais para ativar as células satélites num processo de regeneração de sucesso (82). Em contrapartida, em estudo prévio (58), uma única aplicação de crioterapia, durante 20 minutos, após a lesão por esmagamento do extensor longo dos dedos, retardou a migração de macrófagos no sítio da lesão, assim como os processos de destruição e diferenciação em aproximadamente um dia. Por fim, o tecido regenerado apresentou maior depósito de colágeno. A temperatura tissular foi mensurada e foi observado que a crioterapia provocou uma redução média de $13.3^{\circ} \mathrm{C}$ da temperatura tissular. Uma redução da temperatura abaixo de $10^{\circ} \mathrm{C}$ está associada à diminuição da atividade enzimática da calpaína (83) e, de acordo com os autores, isso teria influenciado nas primeiras fases da degeneração, visto que a calpaína é responsável pela proteólise muscular (58). De qualquer forma, são necessários 
mais estudos a fim de investigar os efeitos da crioterapia no processo de regeneração, especialmente em humanos.

Uma revisão sistemática, realizada por Collins (2008), examinou os efeitos da crioterapia na redução da dor, redução do edema, manutenção da funcionalidade e no intervalo de retorno às atividades (84). Entre os estudos clínicos, alguns apresentaram evidências do benefício da crioterapia na redução da dor e na manutenção da funcionalidade (84). Alguns estudos de modelo animal apontaram que a crioterapia reduziu o edema (84). Contudo, os achados indicaram que não há evidencias suficientes que sugiram o benefício da utilização da crioterapia (84). Outra revisão, realizada por Hubbard e colaboradores (2004), investigou os efeitos da crioterapia no retorno às atividades de trabalho ou de esporte após lesão musculoesquelética (81). Quatro estudos atenderam os critérios de seleção dessa revisão. Em dois estudos a crioterapia significantemente acelerou e melhorou as condições de retorno às atividades (81). Em outro estudo, de acordo com os autores da revisão, a crioterapia apresentou uma tendência de aceleração do retorno (81). Baseados nisso, os autores concluíram que a crioterapia tem um possível efeito positivo no retorno às atividades por interferir potencialmente em mecanismos de controle de dor e de redução da lesão secundária (81). Ambas as revisões citadas apontaram que os estudos encontrados, geralmente apresentam amostras pequenas e limitações metodológicas que interferem na qualidade dos dados disponíveis e aparentemente contribuem para a persistência da lacuna a respeito da efetividade da crioterapia em abordagem funcional $(81,84)$.

O dano oxidativo após a lesão musculoesquelética foi abordado previamente em modelos de lesão por estiramento (9), contusão (14) e isquemia-reperfusão (7). Nesses estudos, os mecanismos bioquímicos pelos quais a crioterapia reduziu o dano oxidativo no tecido muscular foram relacionados com a redução da resposta inflamatória e modulação da função mitocondrial $(7,9,14)$. De fato, a resposta inflamatória após lesão musculoesquelética, acarreta na produção em massa de EROs por macrófagos e neutrófilos para destruir fibras e detritos musculares $(8,30,85)$. Uma vez que crioterapia reduziu a resposta inflamatória, a produção de EROs e o dano oxidativo também foram reduzidos. Em concordância, o presente estudo demonstrou que após a criolesão, a crioterapia foi capaz de reduzir o dano oxidativo, evitando o aumento dos níveis de DCF-RS e TBARS. Os baixos níveis de DCF-RS indicam que a crioterapia foi capaz de reduzir a produção de hidroperóxidos, os quais são responsáveis por iniciar uma cascata de reações complexas que culminam, por exemplo, em peroxidação lipídica das membranas celulares e assim no aumento dos níveis de TBARS (86). É viável analisar o dano oxidativo pela magnitude da peroxidação lipídica, pois as biomembranas são alvos altamente susceptíveis à oxidação das EROs devido à sua estrutura molecular abundante em ligações duplas (42).

Após a lesão musculoesquelética, a mitocôndria conduz a produção de adenosina trifosfato (ATP) à via glicolítica na condição de hipóxia. A via glicolítica é ineficiente para manter o metabolismo adequado e associado à inadequada oferta de substratos, não se 
consegue manter a produção adequada de ATP. A atividade de enzimas do sítio mitocondrial reduz, a mitocôndria entra em colapso e, por sua vez a célula também (52). Em condições de funcionalidade adequada, as enzimas desidrogenases reduzem o MTT a formazan (69). No presente estudo, os níveis de MTT reduzido permaneceram altos nos grupos tratados, em todos os períodos analisados, sugerindo que a crioterapia minimizou o comprometimento da viabilidade celular. Benefícios similares da crioterapia foram observados por Puntel e colaboradores (2011), em que os resultados de viabilidade celular a partir dos níveis de MTT foram associados a indicadores específicos do comprometimento da viabilidade mitocondrial (14). Assim como nos estudos prévios $(7,9,14)$, a crioterapia manteve a atividade enzimática de SOD e CAT e os níveis de grupos -SH não-proteicos próximos aos valores do grupo controle. Esses achados refletem capacidade da crioterapia em reduzir a resposta inflamatória e o dano oxidativo (9).

Alguns estudos têm sugerido que a crioterapia reduz a extensão da área de lesão secundária $(10,13,52)$ e que a lesão primária não poderia sofrer influência terapêutica (26). A área de lesão secundária trata-se da área que não foi diretamente acometida pelo mecanismo de lesão, mas, sim, pela hipóxia tecidual e pela degradação causada por leucócitos, citocinas pró-inflamatórias e EROs $(6,10,30,85)$. Um estudo pioneiro na investigação da lesão muscular secundária por meio de marcadores de estresse foi realizado por Merrick e colaboradores, em 1999 (52). Nesse estudo, foi realizada a aplicação de 5 h consecutivas de crioterapia após lesão muscular por contusão e os resultados demonstraram que a crioterapia reduziu a extensão da lesão secundária (52). Conforme citado em estudos anteriores, uma possível razão para os resultados de efeito positivo da crioterapia na redução da extensão da lesão está relacionada à capacidade dessa estratégia terapêutica em reduzir a temperatura tissular que, por sua vez, reduz a demanda metabólica, a hipóxia e a lesão secundária (10, 13, 52). Contudo, em 2004, Merrick publicou uma revisão a respeito de lesão secundária e questionou se a eficácia da crioterapia não poderia ser explicada pelo resgate ou atraso da morte de células envolvidas na lesão primária, mas que não foram destruídas inicialmente (6). De fato, os achados do presente estudo não permitem distinguir claramente se a crioterapia reduziu as áreas de lesão primária e secundária ou apenas de lesão secundária.

Recentemente, um estudo com humanos investigou o dano oxidativo em resposta a exercício submáximo em ciclo ergômetro seguido por $5 \mathrm{~min}$ de uma única imersão em água gelada (15). De modo similar aos modelos animais $(7,9,14)$, o estudo encontrou uma redução da concentração dos biomarcadores da peroxidação lipídica associada à crioterapia (15). Entre os estudos de modelo animal, encontramos diferentes protocolos de crioterapia (7.9,14). Um deles realizou 2 aplicações de crioterapia com duração de $5 \mathrm{~min}$ e um intervalo de $6 \mathrm{~h}$ entre elas (14); outro realizou 2 aplicações de $5 \mathrm{~min}$ com duração de $12 \mathrm{~h}$ entre elas (9) e um outro realizou 3h de aplicação contínua de crioterapia (7). Apesar desses estudos contribuírem para elucidação dos efeitos da crioterapia sobre o estresse oxidativo, os protocolos não representam a prática clínica, em que as aplicações de 
crioterapia são realizadas intermitentemente com duração de 20-30min (16-19), nas primeiras $72 \mathrm{~h}$ após a lesão (16,32,60-62). Aplicações contínuas de crioterapia com duração de horas estão associadas ao risco de lesão de pele e nervos $(12,57,84)$. Assim como, aplicações de crioterapia acima de 2 horas consecutivas podem aumentar a lesão por hipóxia secundária (56).

Por sua vez, a efetividade do modelo de criolesão no músculo TA dos ratos foi avaliada pela comparação dos resultados das análises entre o grupo controle e os grupos lesão não tratados. O modelo de criolesão demonstrou-se eficaz, tanto que no grupo lesão não tratado encontramos um pico de infiltrado inflamatório no dia 3 , caracterizando a fase aguda da destruição e inflamação da lesão musculoesquelética com sua gradativa resolução após as 72 horas iniciais. Em relação aos níveis de TBARS e MTT reduzido observamos maiores alterações no dia 3 após a lesão. Em contrapartida, os níveis de DCFRS apresentaram aumento a partir do dia 7 com pico no dia 14 após a lesão. Esses resultados sugerem que o aumento da peroxidação lipídica e a redução da viabilidade mitocondrial iniciais poderiam estar acontecendo por EROs não detectáveis no ensaio da DCF-RS (64). Ao passo que uma geração significativa de peróxidos está acontecendo nos dias 7 e 14, momento em que os níveis do sistema de defesa celular, conforme sugerido pela avaliação conjunta dos resultados, já estaria neutralizando a maioria dos mesmos (33).. Vale ressaltar que o índice das EROs é crescente ao longo dos dias avaliados, apesar da densidade do infiltrado inflamatório apresentar-se decrescente no grupo lesão não tratado ao longo dos dias avaliados. Outras análises como as relativas aos mediadores inflamatórios ou às alterações de proteínas e de ácidos nucleicos, podem ser realizadas para se chegar a uma visão mais completa do metabolismo celular/dano celular após a lesão musculoesquelética.

Considerando o sistema antioxidante, observamos que a atividade enzimática da CAT e os níveis -SH não-proteicos, realmente apresentaram alteração no dia 3 após a lesão. Ambas as análises revelam a ativação de componentes de defesa responsáveis pela desintoxicação de peróxido de hidrogênio $\left(\mathrm{H}_{2} \mathrm{O}_{2}\right)$, a fim de evitar um aumento ainda maior da peroxidação lipídica e redução da viabilidade celular. A CAT reduz $\circ \mathrm{H}_{2} \mathrm{O}_{2}$ em baixos níveis de concentração. Porém, em altas concentrações de $\mathrm{H}_{2} \mathrm{O}_{2}$ a glutationa peroxidase (GPx) é responsável por esse processo. A GPx é altamente dependente da glutationa reduzida (GSH). A redução dos níveis de grupos $-\mathrm{SH}$ não-proteicos após a lesão musculoesquelética pode significar uma redução dos níveis de $\mathrm{GSH}$, provavelmente devido ao consumo desses grupos como substrato da GPx (45).

A atividade enzimática da SOD apresentou um aumento progressivo ao longo dos dias avaliados após a lesão, provavelmente como um efeito compensatório ao aumento crescente das EROs. Essa resposta da atividade enzimática da SOD encontrada no nosso estudo não está de acordo em relação a estudos anteriores $(7,9,14)$. Uma possível razão para esse resultado pode ser que o dano causado pela criolesão seja maior do que o dos outros mecanismos, e assim a atividade enzimática da SOD foi ativada em maiores 
proporções. Oliveira e colaboradores (2013) descrevem que a baixa temperatura do mecanismo da criolesão pode alterar a estrutura quartenária das proteínas $(54,87)$.

Um importante biomarcador de lesão muscular é a atividade enzimática de creatina quinase (CK), uma enzima presente principalmente citosol das fibras musculares que expressa amplamente a função celular (88). Carvalho e colaboradores (2010) observaram uma correlação positiva entre aumento da atividade de CK plasmática e os níveis dos marcadores de estresse oxidativo: DCF-RS e TBARS (9). Ao passo que, o efeito antioxidante da crioterapia mostrou estar associado à modulação plasmática da atividade de CK tanto após a lesão muscular por estiramento (9) quanto por contusão (14).

Finalmente, é importante destacar algumas limitações do presente estudo: ausência de um grupo experimental submetido ao procedimento cirúrgico e não submetidos aos protocolos de lesão e de crioterapia; ausência da mensuração da temperatura tissular e corporal; ausência de análise de indicadores de função mitocondrial no tecido muscular esquelético; e ausência da quantificação dos níveis de CK. Além disso, os estudos que investigam a resposta de biomarcadores evolvidos no estresse oxidativo após lesão musculoesquelética são escassos. Dessa forma, foi difícil comparar os nossos resultados e realizar um reflexão crítica baseado na literatura científica atual. Sendo assim, torna-se necessário a realização de mais estudos, especialmente com humanos, a fim de elucidar os efeitos de protocolos de crioterapia similares às recomendações clínicas sobre a bioquímica da regeneração muscular. 


\section{CONCLUSÃO}

Em conclusão, as aplicações intermitentes de crioterapia, nas primeiras 72 horas após criolesão do músculo TA em ratos, reduziram o infiltrado inflamatório e o dano oxidativo. Em termos de aplicações práticas, a crioterapia pode desempenhar um importante papel durante as primeiras fases de regeneração muscular ao limitar a extensão da lesão inerente ao dano oxidativo e resposta inflamatória. 


\section{REFERÊNCIAS}

1.Kieb M, Lorbach O, Engelhardt M. [Muscle injuries: diagnostics and treatments]. Der Orthopade. 2010;39(12):1098-1107.

2.Vranjac A. O impacto dos acidentes e violências nos gastos da saúde. Rev Saúde Pública. 2006;40(3):553-6.

3.Baoge L, Van Den Steen E, Rimbaut S, Philips N, Witvrouw E, Almqvist K F, Vanderstraeten G, Vanden Bossche LC. Treatment of skeletal muscle injury: a review. ISRN orthopedics.2012.

4.Tidball J G. Inflammatory cell response to acute muscle injury. Medicine and science in sports and exercise. 1995;27(7):1022-1032.

5.Clarkson PM \& Hubal MJ. Exercise-induced muscle damage in humans. American journal of physical medicine \& rehabilitation. 2002;81(11):S52-S69.

6.Merrick MA. Secondary injury after musculoskeletal trauma: a review and update. Journal of athletic training. 2002;37(2):209.

7.Puntel GO, Carvalho NR, Dobrachinski F, Salgueiro AC, Puntel RL, Folmer V, Barbosa NBV, Royes LFF, Rocha JBT, Soares FA. Cryotherapy reduces skeletal muscle damage after ischemia/reperfusion in rats. Journal of anatomy. 2013;222(2):223-230.

8.Dröge W. Free radicals in the physiological control of cell function. Physiological reviews 2002;82(1):47-95.

9.Carvalho N, Puntel G, Correa P, Gubert P, Amaral G, Morais J, Royes L, Rocha J, Soares $F$. Protective effects of therapeutic cold and heat against the oxidative damage induced by a muscle strain injury in rats. Journal of sports sciences. 2010;28(9):923-935.

10.Oliveira NM, Rainero EP, Salvini TF. Three intermittent sessions of cryotherapy reduce the secondary muscle injury in skeletal muscle of rat. Journal of sports science \& medicine. 2006;5(2): 228.

11.Vieira A, Oliveira AB, Costa JR, Herrera E, Salvini TF. Cold modalities with different thermodynamic properties have similar effects on muscular performance and activation. Int $\mathrm{J}$ Sports Med. 2013;34(10):873-880.

12.Collins NC. Is ice right? Does cryotherapy improve outcome for acute soft tissue injury?. Emergency Medicine Journal. 2008;25(2):65-68.

13.Oliveira NML, Gava AD, Salvini TF. The effect of intermittent cryotherapy and compression on muscle injuries in rats: a morphometric analysis. Brazilian Journal of Physical Therapy. 2007;11(5):403-409.

14.Puntel GO, Carvalho NR, Amaral GP, Lobato LD, Silveira SO, Daubermann MF, Barbosa NV, Rocha JBT, Soares FA. Therapeutic cold: an effective kind to modulate the oxidative damage resulting of a skeletal muscle contusion. Free radical research 2011;45(2):133-146.

15.Sutkowy P, Augustyńska B, Woźniak A, Rakowski A. Physical exercise combined with whole-body cryotherapy in evaluating the level of lipid peroxidation products and other oxidant stress indicators in kayakers. Oxidative medicine and cellular longevity.2014.

16.Knight, K. L. Cryotherapy in sport injury management. Champaign, IL: Human Kinetics, 1995, pp. 3-98.

17.Swenson C, Swärd L, Karlsson J. Cryotherapy in sports medicine. Scandinavian journal of medicine \& science in sports.1996;6(4):193-200. 
18.Kerr KM, Daily L, Booth L. Guidelines for the management of soft tissue (musculoskeletal) injury with protection, rest, ice, compression and elevation (PRICE) during the first 64 hours. London, UK: Chartered Society of Physiotherapy.1999.

19.Bleakley CM, McDonough SM, MacAuley DC. Cryotherapy for acute ankle sprains: a randomised controlled study of two different icing protocols. British journal of sports medicine. 2006;40(8):700-705.

20.Rahusen FT, Weinhold PS, Almekinders LC. Nonsteroidal anti-inflammatory drugs and acetaminophen in the treatment of an acute muscle injury. The American journal of sports medicine. 2004;32(8):1856-1859.

21.Järvinen TA, Järvinen TL, Kääriäinen $M$, Kalimo $H$, Järvinen $M$. Muscle injuries biology and treatment. The American journal of sports medicine 2005;33(5):745-764.

22. Howatson G, Van Someren K, Hortobagyi T. Repeated bout effect after maximal eccentric exercise. International journal of sports medicine 2007; 28(7): 557-563.

23.Meerding WJ, Mulder S, van Beeck EF. Incidence and costs of injuries in The Netherlands. The European Journal of Public Health. 2006;16(3):271-277.

24.Urso ML. Anti-inflammatory interventions and skeletal muscle injury: benefit or detriment?. Journal of Applied Physiology. 2013;115(6):920-928.

25.Fisher BD, Baracos VE, Shnitka TK, Mendryk SW, Reid DC. Ultrastructural events following acute muscle trauma. Med Sci Sports Exerc. 1990; 22:185-193.

26.Schaser KD, Disch AC, Stover JF, Lauffer A, Bail HJ, Mittlmeier T. (2007). Prolonged superficial local cryotherapy attenuates microcirculatory impairment, regional inflammation, and muscle necrosis after closed soft tissue injury in rats. The American journal of sports medicine. 2007;35(1);93-102.

27.Järvinen TA, Järvinen TL, Kääriäinen $M$, Äärimaa V, Vaittinen $S$, Kalimo $H$, Järvinen $M$. Muscle injuries: optimising recovery. Best Practice \& Research Clinical Rheumatology. 2007;21(2):317-331.

28. Huard J, Li Y, Fu FH. Muscle injuries and repair: current trends in research. The Journal of Bone \& Joint Surgery 2002;84(5):822-832.

29.Prisk V \& Huard J. Muscle injuries and repair: the role of prostaglandins and inflammation. Hisyol Histopathol. 2003;18(4):1243-1256.

30.Peake J, Nosaka KK, Suzuki K. Characterization of inflammatory responses to eccentric exercise in humans. Exerc Immunol Rev. 2005;11:64-85.

31.Tidball JG. Inflammatory processes in muscle injury and repair. American Journal of Physiology-Regulatory, Integrative and Comparative Physiology. 2005;288(2):R345-R353.

32.Pournot H, Bieuzen F, Louis J, Fillard JR, Barbiche E, Hausswirth C. Time-course of changes in inflammatory response after whole-body cryotherapy multi exposures following severe exercise. PloS one 2011;6(7):e22748.

33.Kalyanaraman B. Teaching the basics of redox biology to medical and graduate students: oxidants, antioxidants and disease mechanisms. Redox biology 2013;1(1):244-257.

34.Barreiros ALBS, David JM, David JP. Oxidative stress: relations between the formation of reactive species and the organism's defense. Química nova 2006;29(1): 113-123. 
35.Vignaud A, Cebrian J, Martelly I, Caruelle JP, Ferry A. Effect of anti-inflammatory and antioxidant drugs on the long-term repair of severely injured mouse skeletal muscle. Experimental physiology. 2005; 90(4):487-495.

36.Blaisdell FW. The pathophysiology of skeletal muscle ischemia and the reperfusion syndrome: a review. Vascular. 2002;10(6):620-630.

37.Gillani S, Cao J, Suzuki T, Hak DJ. The effect of ischemia reperfusion injury on skeletal muscle. Injury. 2012;43(6):670-675.

38.de Zwart LL, Meerman JHN, Commandeur JNM, Vermeulen, NPE. Biomarkers of free radical damage: applications in experimental animals and in humans. Free Radical Biology and Medicine 1999;26(1):202-226.

39.Clarkson PM, Thompson HS. Antioxidants: what role do they play in physical activity and health?. The American Journal of Clinical Nutrition 2000;72(2):637s-646s.

40.Gutteridge $\mathrm{J} \&$ Halliwell B. Free radicals and antioxidants in the year 2000: a historical look to the future. Annals of the New York Academy of Sciences. 2000;899(1):136-147.

41.Reed TT. Lipid peroxidation and neurodegenerative disease. Free Radical Biology and Medicine. 2011;51(7):1302-1319.

42.Porter NA, Caldwell SE, Mills KA. Mechanisms of free radical oxidation of unsaturated lipids. Lipids. 1995;30(4):277-290.

43.Bernas T, Dobrucki J. Mitochondrial and nonmitochondrial reduction of MTT: Interaction of MTT with TMRE, JC-1, and NAO mitochondrial fluorescent probes. Cytometry 2002;47(4):236-242.

44.Berridge MV \& Tan AS. Characterization of the cellular reduction of 3-(4, 5dimethylthiazol-2-yl)-2, 5-diphenyltetrazolium bromide (MTT): subcellular localization, substrate dependence, and involvement of mitochondrial electron transport in MTT reduction. Archives of biochemistry and biophysics. 1993;303(2):474-482.

45.Ho E, Galougahi KK, Liu CC, Bhindi R, Figtree GA. Biological markers of oxidative stress: applications to cardiovascular research and practice. Redox biology 2013;1(1):483-491.

46.Banerjee AK, Mandal A, Chanda D, Chakraborti S.Oxidant, antioxidant and physical exercise. Molecular and cellular biochemistry. 2003;253(1-2):307-312.

47.Vertuani S, Angusti A, Manfredini S. The antioxidants and pro-antioxidants network: an overview. Current pharmaceutical design. 2004;10(14):1677-1694.

48.Merrick MA, Jutte LS, Smith ME. Cold modalities with different thermodynamic properties produce different surface and intramuscular temperatures. Journal of Athletic Training. 2003;38(1):28.

49. Versey NG, Halson SL, Dawson BT. Water Immersion Recovery for Athletes: Effect on Exercise Performance and Practical Recommendations. Sport Med, 2013;43:1101-1130

50.Bleakley C, McDonough S, Gardner E, Baxter GD, Hopkins JT, Davison GW. Cold-water immersion (cryotherapy) for preventing and treating muscle soreness after exercise. Cochrane Database Syst Rev. 2012;2(2):CD008262

51.Torres R, Ribeiro F, Duarte JA, Cabri JM. Evidence of the physiotherapeutic interventions used currently after exercise-induced muscle damage: systematic review and metaanalysis. Physical Therapy in Sport 2012;13(2):101-114. 
52. Merrick MA, Rankin JM, Andres FA, Hinman CL. A preliminary examination of cryotherapy and secondary injury in skeletal muscle. Medicine and science in sports and exercise. 1999;31(11):1516-1521.

53.Westermann S, Vollmar B Thorlacius H, Menger MD. Surface cooling inhibits tumor necrosis factor- $\alpha$-induced microvascular perfusion failure, leukocyte adhesion, and apoptosis in the striated muscle. Surgery. 1999;126(5): 881-889.

54.Oliveira NMLD, Durigan JLQ, Munin FS, Schwantes MLB, Salvini TDF. The effect of intermittent cryotherapy on the activities of citrate synthase and lactate dehydrogenase in regenerating skeletal muscle. Brazilian Archives of Biology and Technology. 2013;56(1):6168.

55.Okasa J, Rintamaki H, Rissanen S. Muscle performance and electromyogram activity of the lower leg muscles with different levels of cold exposure. Eur J Appl Physiol. 1997;75(6):484-490.

56.Farry PJ, Prentice NG, Hunter AC, Wakelin CA. Ice treatment of injured ligament: an experimental model. N Z Med J. 1980;91:12-14.

57.Knobloch K, Spies M, Busch KH, Vogt PM. Comment on report from Schaser and coworkers. Am J Sports Med. 2007;35:2-3.

58.Takagi R, Fujita N, Arakawa T, Kawada S, Ishii N, Miki A. Influence of icing on muscle regeneration after crush injury to skeletal muscles in rats. J Appl Physiol. 2011;110(2):382-8.

59.Tidball JG. Mechanisms of muscle injury, repair, and regeneration.Comprehensive Physiology.2011; 1:2029-2062.

60.Eston R, Peters D. Effects of cold water immersion on the symptoms of exercise-induced muscle damage. Journal of sports sciences 1999;17(3):231-238.

61.Oakley ET, Pardeiro RB, Powell JW, Millar AL. The effects of multiple daily applications of ice to the hamstrings on biochemical measures, signs, and symptoms associated with exercise-induced muscle damage. The Journal of Strength \& Conditioning Research. 2013; 27(10): 2743-2751.

62.Tseng CY, Lee JP, Tsai YS, Lee SD, Kao CL, Liu TC, Lai CH, Harris MB, Kuo, C. H. Topical Cooling (Icing) Delays Recovery From Eccentric Exercise-Induced Muscle Damage. The Journal of Strength \& Conditioning Research. 2013;27(5):1354-1361.

63.Durigan JL, Peviani SM, Russo TL, Delfino GB, Ribeiro JU, Cominetti MR, Selistre-deAraujo HS, Salvini TF. Effects of alternagin-C from Bothrops alternatus on gene expression and activity of metalloproteinases in regenerating skeletal muscle. Toxicon. 2008; 52: 68794.

64.Myhre O, Andersen JM, Aarnes H, Fonnum F. Evaluation of the probes 2', 7'dichlorofluorescin diacetate, luminol, and lucigenin as indicators of reactive species formation. Biochemical pharmacology. 2003;65(10):1575-1582.

65. Halliwell B \& Gutteridge JMC. (2007). Measurement of reactive species.In: Halliwell B \& Gutteridge JMC. Free radicals in biology and medicine, $4^{\underline{a}}$ edição. Oxford University Press, Oxford, 268-340.

66.Pérez-Severiano F, Rodrígues-Pérez M, Pedraza-Chaverrí J, Maldonado PD, MedinaCampos ON, Ortíz-Plata A, Sánchez-Garc í a A, Villeda-Hern á ndez J, Galv á n-Azarte S, Aguilera P, Santamar í a A. S-Allylcysteine, a garlic-derived antioxidant, ameliorates quinolinic acid-induced neurotoxicity and oxidative damage in rats. Neurochem Int. 2004;45:1175 - 1183 . 
67.Ohkawa H, Ohishi N, Yagi K. Assay for lipid peroxides in animal tissues by thiobarbituric acid reaction. Analytical biochemistry. 1979;95(2):351-358.

68.Shearman MS. Cellular MTT reduction distinguishes the mechanism of action of $\beta$ amyloid from that of tachykinin receptor peptides.Neuropeptides. 1996;30(2):125-132.

69.Mosmann T. Rapid colorimetric assay for cellular growth and survival: application to proliferation and cytotoxicity assays. Journal of immunological methods. 1983;65(1):55-63.

70.Misra HP\& Fridovich I. The role of superoxide anion in the autoxidation of epinephrine and simple assay for superoxide dismutase. J Biol Chem. 1972;247:3170-3175.

71.Aebi, H. Catalase in vitro. Methods in enzymology. 1984;105;121-126.

72.Sies, H. Oxidative stress: oxidants and antioxidants. Experimental physiology. 1997;82(2):291-295.

73.Vertuani S, Angusti A, Manfredini S. The antioxidants and pro-antioxidants network: an overview. Current pharmaceutical design. 2004;10(14):1677-1694.

74.Ellman GL.Tissue sulfhydryl groups. Arch Biochem Biophys. 1952;(82):70-77.

75.Lowry OH, Rosebrough NJ, Farr AL, Randall RJ. Protein measurement with the Folin phenol reagent. J biol Chem. 1951;193(1): 265-275.

76.Crystal NJ, Townson DH, Cook SB, LaRoche, DP. Effect of cryotherapy on muscle recovery and inflammation following a bout of damaging exercise. European journal of applied physiology. 2013;113(10): 2577-2586.

77.Banfi G, Melegati G, Barassi A, Dogliotti G, d'Eril GM, Dugué B, Corsi MM. Effects of whole-body cryotherapy on serum mediators of inflammation and serum muscle enzymes in athletes. Journal of Thermal Biology. 2009;34(2):55-59.

78.Khoshnevis S, Craik NK, Diller KR. (2014). Cold-induced vasoconstriction may persist long after cooling ends: an evaluation of multiple cryotherapy units. Knee Surgery, Sports Traumatology, Arthroscopy. 2014:1-9.

79.Curl WW, Smith BP, Marr A, Rosencrance E, Holden M, Smith TL. The effect of contusion and cryotherapy on skeletal muscle microcirculation. The Journal of sports medicine and physical fitness. 1997;37(4):279-286.

80.Deal DN, Tipton J, Rosencrance E, Curl WW, Smith TL. Ice reduces edema. The Journal of Bone \& Joint Surgery. 2002;84(9):1573-1578.

81.Hubbard TJ, Aronson SL, Denegar CR. Does cryotherapy hasten return to participation? A systematic review. Journal of athletic training. 2004;39(1):88.

82.Moyer AL \& Wagner KR. (2011). Regeneration versus fibrosis in skeletal muscle. Current opinion in rheumatology. 2011;23(6):568-573.

83.Nakayama A. Thermal physiology. Rikogakusha, Tokyo, 1981.

84.Collins NC. Is ice right? Does cryotherapy improve outcome for acute soft tissue injury?. Emergency Medicine Journal. 2008;25(2):65-68.

85.Ferreira-Junior JB, Bottaro M, Loenneke JP, Vieira A, Vieira CA, Bemben MG. Could whole-body cryotherapy (below- $100^{\circ}$ C) improve muscle recovery from muscle damage?. Frontiers in physiology, 2014;5.

86. Halliwell B. Reactive species and antioxidants. Redox biology is a fundamental theme of aerobic life. Plant physiology. 2006;141(2):312-322. 
87.Alexandrov K. Effects of inducers and inhibitors of the benzo(a)pyrene hydroxylase of isolated rat liver nuclei and nuclear envelopes on the binding of benzo(a)pyrene to DNA. Eur. J. Cancer. 1977;13(8):847-853.

88.Brancaccio P, Lippi G, Maffulli N. Biochemical markers of muscular damage. Clinical Chemistry and Laboratory Medicine. 2010;48(6):757-767. 


\section{ANEXOS \\ ANEXO I - Aprovação do Comitê de Ética em Experimentação Animal}

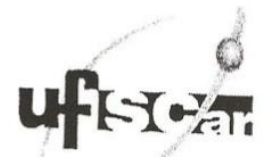

UNIVERSIDADE FEDERAL DE SÃO CARLOS

PRÓ-REITORIA DE PESQUISA

Comissão de Ética no Uso de Animais

Via Washington Luis, km. 235 - Caixa Postal 676

Fones: (016) 3351.8109/3351.8110

Fax: (016) 3361.3176

CEP 13560-970 - São Carlos - SP - Brasil

ceua@ufscar.br - www.propq.ufscar.br

Protocolo no. 059/2010

A Presidente da Comissão de Ética no Uso de Animais da Universidade Federal de São Carlos - CEUA/UFSCar analisou e APROvou "ad referendum" o pedido formulado pelo (a) pesquisador (a) João Luiz Quagliotti Durigan referente ao projeto "Efeito de crioterapia sobre a regeneração muscular do músculo tibial anterior em ratos.".

São Carlos, 1 de março de 2011.

Profa. Dra. Luciana Thie Seki Dias

Presidente da Comissão de Ética no Uso de Animais

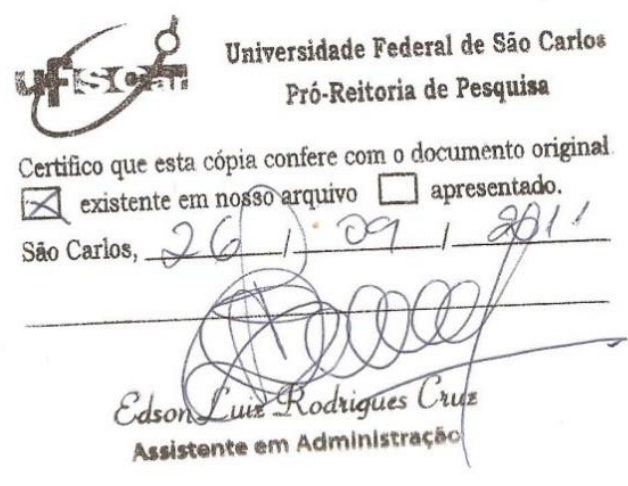

